\title{
Decrease of chemerin by aerobic exercise improved glycolipid metabolism of diabetes through increasing key metabolism enzymes and protein mediated by PPARY
}

\section{Xiaojing Lin}

Shanghai University of Sport School of Kinesiology

Lijun Yin

Shanghai University of Sport School of Kinesiology

Jing Qu

Shanghai University of Sport School of Kinesiology

Xiaohui Wang ( $\nabla$ wangpan96@126.com )

Shanghai University of Sport https://orcid.org/0000-0001-8355-3871

\section{Research Article}

Keywords: chemerin, aerobic exercise, glycolipid metabolism, CMKLR1, PPARy, ATGL, LPL, GLUT4

Posted Date: March 10th, 2021

DOI: https://doi.org/10.21203/rs.3.rs-288726/v1

License: (c) (1) This work is licensed under a Creative Commons Attribution 4.0 International License.

Read Full License 


\section{Abstract}

Background: Our previous work indicated that exercise-induced reduction of chemerin (an adipokine and chemokine) played an important role in the improvement of glycolipid metabolism of diabetic rats, and this manuscript are to: (1) clarify peroxisome proliferator-activated receptor (PPARY) mediating the regulation of decreased chemerin on glycolipid metabolism key enzymes (including adipose triglyceride lipase (ATGL), lipoprotein lipase (LPL), glucose transporter 4 (GLUT4) and phosphoenolpyruvate carboxykinase (PEPCK)) in diabetic rats; (2) demonstrate the crucial role of decreased chemerin on exercise-induced improvement of glycolipid metabolism in diabetic mice by exogenous chemerin supplement (for only mice-resource chemerin available).

Methods: After establishing type 2 diabetes models, diabetic SD rats were randomly divided into 4 groups: diabetes (DM), exercised diabetes (EDM), EDM plus PPARy agonist pioglitazone (EDP), and EDM plus PPARy antagonist GW9662 (EDG), while diabetic ICR mice divided into 3 groups: DM, EDM and EDM plus exogenous chemerin supplementation (EDC). The exercised rodents participated in 4-week (rats) or 6-week (mice) moderate-intensity aerobic exercise, and at $30 \mathrm{~min}$ before exercise pioglitazone $(10 \mathrm{mg} / \mathrm{kg})$ and GW9662 $(1 \mathrm{mg} / \mathrm{kg})$ were intragastrically administered to EDP and EDG rats respectively, while recombinant mouse chemerin $(8 \mu \mathrm{g} / \mathrm{kg})$ was intraperitoneally injected to $\mathrm{C}$ and EDC mice. Glycolipid metabolism indexes were determined. Serum chemerin and the protein levels of the above molecules in metabolic organs (liver, gastrocnemius and epididymal fat) were detected by ELISA and Western blot, respectively.

Results: (1) In diabetes rats, aerobic exercise-induced increases of ATGL and LPL (livers and gastrocnemius) as well as decrease of PEPCK (livers) were reversed by GW9662, and further strengthened by pioglitazones. (2) In diabetes mice, aerobic exercise also significantly increased the levels of PPARY, ATGL, LPL and GLUT4 as well as decreased the level of PEPCK; furthermore, the changes of the above molecules and improvements of glycolipid metabolism and fatty liver were partly reversed by exogenous chemerin.

Conclusion: The decreased chemerin played important roles in aerobic exercise-induced improvements of glycolipid metabolism and fatty liver in diabetes, through increasing glycolipid metabolism key enzymes and protein (ATGL, LPL and GLUT4) mediated by PPARg.

\section{Introduction}

Chemerin, a novel adipokine and chemokine, is primarily produced in liver and adipocytes and exerts its multiply functions such as modulating adipogenesis, lipolysis, glycolipid metabolism, insulin resistance (IR) and inflammation mainly through its receptor chemokine-like receptor 1 (CMKLR1)[1]. Numerous clinical studies confirmed the greatly elevated serum chemerin in multiple metabolic and inflammatory diseases including obesity[2], type 2 diabetes[3], atherosclerosis[4], metabolic syndrome[5], cardiovascular disease[6] and nonalcoholic fatty liver disease[7], and chemerin level was positively 
associated with the severity of these inflammatory diseases[8]. Besides serum chemerin, the increases of chemerin/CMKLR1 in liver, muscle and fat were likely to be closely related to glycolipid metabolism disorders and obesity-related chronic inflammation in the rats and mice with obesity or obesity related diseases, [9-11].

Exercise has positive effects on preventing and treating obesity and obesity related diseases[12, 13]. The benefits of exercise on improvement of glycolipid metabolism and suppression of chronic inflammation have been confirmed in patients with obesity $[14,15]$ and diabetes[16, 17], but the underlying mechanisms are not fully clarified. An increasing number of evidence has demonstrated that exercise induced decline of serum chemerin[18-20], and the decrease of serum chemerin is likely to be associated with the improvement of glycolipid metabolism and alleviation of inflammation not only in normal elderly[21], but also in obese[2, 22] and diabetic patients[23]. Our previous study further indicated that exercise-induced decreases of serum chemerin and the levels of chemerin/CMKLR1 in peripheral metabolic organs were associated with the improvement of glycolipid metabolism in obese and diabetic rats[10].

However, the mechanisms of exercise-induced lower of chemerin improved glycolipid metabolism of obesity and diabetes are still unknown. Glycolipid metabolism key enzymes and protein exert vital roles in glycolipid anabolism, catabolism and transportation. For example, adipose triglyceride lipase (ATGL) plays important roles in liver glycolipid metabolism and lipid decomposition by affecting lipogenesis, glycolysis and gluconeogenesis [24]; lipoprotein lipase (LPL) is a key speed-limiting enzyme for the breakdown of chylomicron and TG in blood as well as the produce of free fatty acids (FFA) for cellular uptake and utilization[25, 26]; phosphoenolpyruvate carboxykinase (PEPCK) is a key enzyme in gluconeogenesis by promoting the production of glucose from pyruvate in hepatic parenchymal cells[27]; and glucose transporter 4 (GLUT4), a principal glucose transporter protein, plays a key role in regulating whole body glucose homeostasis through mediating insulin-stimulated glucose transport into skeletal muscle thus decreasing blood glucose[28, 29].

Furthermore, ATGL and LPL are peroxisome proliferator-activated receptor y (PPARY) target genes, and PEPCK and GLUT4 were also reported to be regulated by PPARY. PPARY, a ligand-activated nuclear receptor, has been identified as a therapeutic target for obesity, hyperlipidemia and diabetes for the dual functions of regulating glycolipid metabolism[30,31] and inhibiting inflammation[32, 33]. Exercise increased PPARy in the liver, muscle and circulating monocytes, which might be related to the decreases of IR and hepatic lipid content[34] and enhancement of glucose uptake, FFA oxidation and insulin sensitivity of skeletal muscle in obese rats[35], as well as prevention of type 2 diabetes in human[33]. It's worth mentioning that chemerin is considered as a novel PPARY target gene in promoting mesenchymal stem cell adipogenesis in vitro [36], and PPARy inhibited chemerin secretion from adipocytes by more than $80 \%$ [37]. But other literatures reported that in vitro chemerin promoted preadipocyte differentiation and maturation by up-regulating the levels of PPARY[36, 38], indicated an interaction between chemerin and PPARY. 
Therefore, we speculate that the effects of exercise-induced decreased chemerin on improvements of glycolipid metabolism in diabetes may be fulfilled through PPARY-mediated regulations on ATGL, LPL, PEPCK and GLUT4. To verify our hypothesis, the current study firstly determined the influences of exercise on the levels of PPARY, ATGL, LPL and PEPCK in DM rats, then explored the indispensability of PPARy on exercise-induced changes of the above enzymes and protein using PPARY antagonist GW9662 and PPARY agonist pioglitazone, lastly treated diabetes mice with exogenous chemerin (for only mouse commercial recombinant chemerin available) to demonstrate the roles of reduced chemerin in exerciseinduced improvements of glycolipid metabolism in diabetes and to further explore the mechanisms: PPARY-mediated regulations on ATGL, LPL, PEPCK andGLUT4?

\section{Material And Methods}

\section{Animals}

One hundred and two male Sprague-Dawley (SD) rats (190-210 g weight) were purchased from Beijing Vital River laboratory animal technology Co. Ltd., and 70 male ICR (30-35g weight) mice were purchased from Jiansu GemPharmatech Co. Ltd.. All the animals were housed under standard specific pathogen free (SPF) conditions with $12 \mathrm{~h}: 12 \mathrm{~h}$ light and dark cycles and food and water were provided ad libitum.

\section{Establishment of type 2 diabetes rats and mice and grouping}

Type 2 diabetes rats were established by high fat diet (HFD) feeding combined with STZ injection, and the details were shown in our previous article[10]. Forty successfully established diabetes rats were randomly divided into four groups of 10 rats each: diabetes mellitus group (DM), exercised diabetes mellitus group (EDM), EDM plus PPARy agonist pioglitazone group (EDP), and EDM plus PPARY antagonist GW9662 group (EDG) to clarify whether PPARy mediated exercise-induced decrease of chemerin.

For demonstrating the effects of reduced chemerin in aerobic exercise-induced improvements of glycolipid metabolism in diabetes and exploring its mechanisms (glycolipid metabolism key enzymes and proteins), type 2 diabetes model mice were established by HFD plus STZ injection due to only mouse exogenous chemerin available. In detail, ICR mice were randomly divided into control group $(n=24)$ and high fat diet (HFD) group $(n=46)$ after acclimating to laboratory condition for 3 days, and were fed ad libitum by 6-week standard diet and high-fat $60 \mathrm{kcal} \%$ fat diet (PD6000, purchased from Changzhou SYSE Bio-Tec. Co., Ltd.), respectively. Then, the 46 mice from HFD group were injected intraperitoneally with STZ (Sigma, St. Louis, MO, USA) at a dose of $100 \mathrm{mg} / \mathrm{kg}$ body weight[39] to establish diabetes mice, and 27 mice showed fasting hyperglycemia (fasting blood glucose, FBG) $>11.1 \mathrm{mmol} / \mathrm{L}$ at 3 and 7 day post-injection were considered as diabetes mice. Twenty-two control mice were randomly divided into 3 groups: control group (Con, $n=8)$, exercised control group $(E, n=8)$ and exogenous chemerin group $(C, n$ 
= 8), while 27 diabetes mice were randomly divided into diabetes mellitus group ( $D M, n=8)$, exercised $D M$ group (EDM, $n=9)$ and EDM plus exogenous chemerin group $(E D C, n=10)$.

\section{Exercise intervention, and supplementations of PPARY agonist and antagonist as well as exogenous mouse chemerin}

The SD rats in the groups of Con, OB and DM kept sedentary life, while EOB, EDM, EDP and EDG rats participated in moderate-intensity aerobic exercise on a treadmill with gradually increased load, once a day and 6 days/week, 4 weeks in total, and at 30 min before exercise the rats in EDP and EDG groups were intragastrically administered $10 \mathrm{mg} / \mathrm{kg}$ body weight of PPARy agonist pioglitazone and $1 \mathrm{mg} / \mathrm{kg}$ body weight of PPARY antagonist GW9662 (both from MedChem Express, NJ, USA), respectively. During the 4-week intervention period, one rat in EDG group was accidently squeezed to death in the gap between the runways of treadmill and six rats from the four groups died probably to be associated with diabetes, so finally 9, 8, 9 and 7 rats were involved in the analysis of results in DM, EDM, EDP and EDG rats groups, respectively.

The ICR mice in Con, $C$ and DM groups kept sedentary life while E, EDM and EDC mice participated in moderate-intensity aerobic exercise on a treadmill with gradually increasing intensity and duration, once a day and 6 days per week, lasts for 6 weeks, and all the mice in C and EDC groups received intraperitoneal injection of recombinant mouse chemerin (R\&D SYSTEMS, MN, USA) at $8 \mu \mathrm{g} / \mathrm{kg} /$ day body weight prior 30 min to each exercise session from the third exercise intervention and lasting for 3-week until the end of exercise intervention.

\section{Determination of glycolipid metabolism index}

Lipid metabolism index including serum triglyceride (TG), total cholesterol (TC), high-density lipoprotein cholesterol (HDL) and low-density lipoprotein cholesterol (LDL) were detected by Nanjing Jiancheng Bioengineering Institute. Glucose metabolism index such as FBG and fasting insulin (FINS) were measured by glucose meter (Roche Accu-Chek Performa, Germany) and ELISA kit, respectively. The variance coefficient of the mouse insulin ELISA kit (Nanjing Jiancheng Bioengineering Institute, China) was $<10 \%$ in intra-assay and $<12 \%$ in inter-assay. IR was estimated by homeostasis model assessment of IR (HOMA-IR), calculating by the formula: = FBG $(\mathrm{mmol} / \mathrm{L}) \times \mathrm{FINS}(\mu \mathrm{U} / \mathrm{ml}) / 22.5$.

\section{Detection of serum chemerin by ELISA}

Serum levels of chemerin in the mice were measured by ELISA according to the manufacturer's instruction.

The variance coefficient of the mouse chemerin ELISA Kit (R\&D System, MN, USA) was $<10 \%$ in intraassay and $<10 \%$ in inter-assay.

\section{Western blot}


About $50 \mathrm{mg}$ of liver and gastrocnemius, and $100 \mathrm{mg}$ of epididymal fat were cut into pieces and homogenized with a homogenizer after adding $500 \mu \mathrm{L}$ of RIPA Lysis Buffer containing $1 \mathrm{mmol} / \mathrm{L}$ phenylmethanesulfonyl fluoride (PMSF) and $2 \mathrm{mmol} / \mathrm{L}$ protease and phosphatase inhibitor cocktail for mammalian (Beyotime Biotechnology, Shanghai, China) to extract total protein. The lysates were briefly sonicated on ice and centrifuged at $12000 \mathrm{rpm}$ for $20 \mathrm{~min}$, then the liquid supernatant was transfer to another EP tube and centrifuged at $12000 \mathrm{rpm}$ for $20 \mathrm{~min}$.

Supernatants were collected and protein concentration was measured using a BCA protein assay kit (Beyotime Biotechnology, Shanghai, China) according to the manufacturer's instruction.

Extracts of liver $(40 \mu \mathrm{g})$, gastrocnemius $(50 \mu \mathrm{g})$ and perirenal fat $(60 \mu \mathrm{g})$ were fractionated on $10 \%$ SDSPAGE gels for detecting all the molecules except chemerin on 15\% SDS-PAGE gel. The resolved protein were electrotransfered onto nitrocellulose membranes, blocked with $5 \%$ nonfat milk for $2 \mathrm{~h}$, and then incubated overnight at $4{ }^{\circ} \mathrm{C}$ with primary antibodies against chemerin (1:2000), LPL and ATGL (1:1000, R\&D System, MN, USA), CMKLR1 and PPARY (1:1000, abcam Company, UK), GLUT4 and $\beta$-actin (1;1000, Cell Signaling Technology, MA, USA), PEPCK (1:1000, Santa cruz Biotechnology, CA, USA), and GAPDH (1:10000, Zen Bioscience, Chengdu, China). The blots were washed for four times, 5 min each time, with Tri-buffered saline with $0.1 \%$ Tween 20 (TBST) and incubated with horseradish peroxidase (HRP) conjugated secondary antibodies for $1.5 \mathrm{~h}$ at room temperature. The blots were washed again as described above, developed with Immobilon Western chemiluminescent HRP substrate (Millipore, MA, USA), and visualized by automatic chemiluminescence image analysis system (Tanon Biotechnology, Shanghai, China). The density of bands was determined using Imagel software and normalized against $\beta$-actin or GAPDH.

\section{Statistical analysis}

Statistical analysis of data was performed using SPSS for Windows 21.0 software package (IBM Corporation, Armonk, NY, USA). All the data were expressed as mean \pm SD, and the levels of statistical significance was set as $p<0.05$. Mean values in different groups with body weight and FBG were compared using two-way repeated measures analysis of variance (ANOVA). Other data were analyzed using one-way ANOVA and post hoc comparisons using least significant difference (LSD)-t test.

\section{Results}

\section{Successful establishment of diabetes model rats and mice}

Diabetes model rats were judged according to fasting hyperglycemia ( $F B G>11.1 \mathrm{mmol} / \mathrm{L}$ ) at 3 and 7 day post-injection after HFD feeding in combination with STZ injection, and the details showed in our published article[10].

For mice, the mean FBG of DM model mice was increased by $13.4 \mathrm{mmol} / \mathrm{L}$, higher than that of diabetes criteria of FBG $>11.1 \mathrm{mmol} / \mathrm{L}(p<0.01)$. Furthermore, the DM mice had diabetes symptoms such as excessive appetite (daily intake: DM $6.01 \pm 0.84 \mathrm{~g}$ vs Con $4.21 \pm 0.33 \mathrm{~g}$ ), weight loss (DM from baseline 
$38.69 \pm 3.42 \mathrm{~g}$ to 6 th week $37.81 \pm 4.77 \mathrm{~g}$ vs Con from baseline $42.11 \pm 2.31 \mathrm{~g}$ to 6 th week $46.02 \pm 2.85 \mathrm{~g}$ ) and polyuria. These results indicated the successful establishment of DM models mice.

Aerobic exercise changed the protein levels of ATGL, LPL and PEPCK in the liver and gastrocnemius of diabetic rats, which were reversed by PPARY antagonist and promoted by PPARY agonist

We found that the protein levels of ATGL and LPL were up-regulated in the liver and gastrocnemius while PEPCK was down-regulated in the liver of DM rats after 4-week aerobic exercise (Fig. 1). Actually, in our obesity model rats established by HFD feeding, similar results were found (Fig. 1).

Furthermore, in EDM rats, the exercise-induced increases of ATGL and LPL in the livers and gastrocnemius as well as decrease of PEPCK in the livers were reversed by PPARY antagonist GW9662, and further strengthened by PPARY agonist pioglitazone (Fig. 2).

Exogenous chemerin treatment partly reversed the exercise-induced change in body fat and improvements of glycolipid metabolism and fatty liver in diabetes mice

The mean body weights of DM mice was significantly decreased compared to Con mice, and exogenous chemerin treatment and exercise had no influence on body weight in diabetic mice (Fig. 3); however, exogenous chemerin treatment (from the third week of exercise intervention and lasting for 3-week until the end of exercise intervention) partly reversed the 6-week exercise induced increase of body fat rate (body fat/body weight ratio) in DM mice (Table 1). In addition, no significant difference was found in daily food consumption between $C$ and Con $(4.41 \pm 0.91 \mathrm{~g}$ vs $4.77 \pm 0.81 \mathrm{~g})$ as well as between EDC and EDM $(3.85 \pm 0.65 \mathrm{~g}$ vs $4.48 \pm 0.91 \mathrm{~g})$ mice, indicated no influence of chemerin on food intake of Con and DM mice. 
Table 1

Effects of exogenous chemerin treatment on body fat of exercised diabetes mice $(x \pm S D)$

\begin{tabular}{|c|c|c|c|c|c|c|}
\hline & $\begin{array}{l}\text { Con } \\
(n=8)\end{array}$ & $\begin{array}{l}C \\
(n=8)\end{array}$ & $\begin{array}{l}E \\
(n=8)\end{array}$ & $\begin{array}{l}\text { DM } \\
(n=8)\end{array}$ & $\begin{array}{l}\text { EDM } \\
(n=9)\end{array}$ & $\begin{array}{l}\text { EDC } \\
(n=10)\end{array}$ \\
\hline Fat (g) & $\begin{array}{l}7.68 \pm \\
1.98\end{array}$ & $\begin{array}{l}7.62 \pm \\
1.06\end{array}$ & $\begin{array}{l}3.35 \pm \\
1.06^{\star \star}\end{array}$ & $\begin{array}{l}3.61 \pm \\
0.89^{* \star}\end{array}$ & $\begin{array}{l}4.86 \pm \\
0.70^{\#}\end{array}$ & $\begin{array}{l}4.02 \pm \\
1.46\end{array}$ \\
\hline Fat/body weight (\%) & $\begin{array}{l}16.57 \pm \\
4.03\end{array}$ & $\begin{array}{l}16.67 \pm \\
2.06\end{array}$ & $\begin{array}{l}7.38 \pm \\
2.61^{\star \star}\end{array}$ & $\begin{array}{l}9.00 \pm \\
1.92^{\star \star}\end{array}$ & $\begin{array}{l}11.00 \pm \\
3.60^{\#}\end{array}$ & $\begin{array}{l}9.67 \pm \\
2.95 \triangle\end{array}$ \\
\hline Lean (g) & $\begin{array}{l}34.53 \pm \\
2.52\end{array}$ & $\begin{array}{l}34.20 \pm \\
1.89\end{array}$ & $\begin{array}{l}38.97 \pm \\
2.63^{\star \star}\end{array}$ & $\begin{array}{l}32.61 \pm \\
3.65\end{array}$ & $\begin{array}{l}31.43 \pm \\
2.84\end{array}$ & $\begin{array}{l}33.74 \pm \\
1.44\end{array}$ \\
\hline Lean/body weight (\%) & $\begin{array}{l}75.14 \pm \\
4.01\end{array}$ & $\begin{array}{l}75.00 \pm \\
2.00\end{array}$ & $\begin{array}{l}84.00 \pm \\
2.07^{\star *}\end{array}$ & $\begin{array}{l}81.38 \pm \\
2.20^{\star \star}\end{array}$ & $\begin{array}{l}80.33 \pm \\
3.42\end{array}$ & $\begin{array}{l}81.89 \pm \\
2.66\end{array}$ \\
\hline Perirenal fat (g) & $\begin{array}{l}0.55 \pm \\
0.16\end{array}$ & $\begin{array}{l}0.45 \pm \\
0.08^{*}\end{array}$ & $\begin{array}{l}0.15 \pm \\
0.06^{\star \star}\end{array}$ & $\begin{array}{l}0.10 \pm \\
0.03^{\star \star}\end{array}$ & $\begin{array}{l}0.15 \pm \\
0.05\end{array}$ & $\begin{array}{l}0.09 \pm \\
0.03\end{array}$ \\
\hline $\begin{array}{l}\text { Perirenal fat/body } \\
\text { weight (\%) }\end{array}$ & $\begin{array}{l}1.20 \pm \\
0.32\end{array}$ & $\begin{array}{l}0.99 \pm \\
0.18^{*}\end{array}$ & $\begin{array}{l}0.32 \pm \\
0.15^{\star \star}\end{array}$ & $\begin{array}{l}0.24 \pm \\
0.07^{\star \star}\end{array}$ & $\begin{array}{l}0.38 \pm \\
0.16\end{array}$ & $\begin{array}{l}0.23 \pm \\
0.08\end{array}$ \\
\hline Epididymal fat (g) & $\begin{array}{l}1.46 \pm \\
0.46\end{array}$ & $\begin{array}{l}1.74 \pm \\
0.31\end{array}$ & $\begin{array}{l}0.79 \pm \\
0.28^{\star \star}\end{array}$ & $\begin{array}{l}0.65 \pm \\
0.16^{\star \star}\end{array}$ & $\begin{array}{l}0.84 \pm \\
0.12\end{array}$ & $\begin{array}{l}0.71 \pm \\
0.37\end{array}$ \\
\hline $\begin{array}{l}\text { Epididymal fat/body } \\
\text { weight (\%) }\end{array}$ & $\begin{array}{l}3.16 \pm \\
0.94\end{array}$ & $\begin{array}{l}3.83 \pm \\
0.77\end{array}$ & $\begin{array}{l}1.72 \pm \\
0.65^{\star \star}\end{array}$ & $\begin{array}{l}1.56 \pm \\
0.39^{* \star}\end{array}$ & $\begin{array}{l}2.15 \pm \\
0.22^{\#}\end{array}$ & $\begin{array}{l}1.68 \pm \\
0.78\end{array}$ \\
\hline
\end{tabular}

As shown in Fig. 4, aerobic exercise and exogenous chemerin treatment had no influence on the FBG levels of normal mice, but at 6th week of exercise intervention, the exercise-induced decrease of FBG in DM mice was totally reversed by exogenous chemerin treatment in EDM mice. Similarly, the exerciseinduced improvements of glucose metabolism index (insulin and HOMAIR) and lipid metabolism index (TC and LDL) in EDM mice were totally reversed by exogenous chemerin treatment (Table 2). These results indicated that decreased chemerin mediated exercise-induced improvements of glycolipid metabolism in diabetic mice. 
Table 2

Effects of exogenous chemerin treatment on the levels of blood glucose and blood lipids of exercised diabetes mice $(x \pm S D)$

\begin{tabular}{|c|c|c|c|c|c|c|}
\hline & $\begin{array}{l}\text { Con } \\
(n=8)\end{array}$ & $\begin{array}{l}C \\
(n=8)\end{array}$ & $\begin{array}{l}E \\
(n=8)\end{array}$ & $\begin{array}{l}\text { DM } \\
(n=8)\end{array}$ & $\begin{array}{l}\text { EDM } \\
(n=9)\end{array}$ & $\begin{array}{l}\text { EDC } \\
(n=10)\end{array}$ \\
\hline \multicolumn{7}{|c|}{ Glucose metabolism index } \\
\hline $\begin{array}{l}\text { FBG } \\
\text { (mmol/L) }\end{array}$ & $\begin{array}{l}5.35 \pm \\
0.89\end{array}$ & $\begin{array}{l}5.84 \pm \\
0.56\end{array}$ & $4.80 \pm 0.77$ & $\begin{array}{l}18.21 \pm \\
3.91^{* *}\end{array}$ & $\begin{array}{l}15.12 \pm \\
3.28^{\#}\end{array}$ & $\begin{array}{l}21.18 \pm \\
3.48 \triangle \triangle\end{array}$ \\
\hline FINS $(\mu \mathrm{lU} / \mathrm{ml})$ & $\begin{array}{l}10.95 \pm \\
2.10\end{array}$ & $\begin{array}{l}12.32 \pm \\
3.44\end{array}$ & $\begin{array}{l}11.63 \pm \\
2.42\end{array}$ & $\begin{array}{l}20.77 \pm \\
6.28^{\star *}\end{array}$ & $\begin{array}{l}13.83 \pm \\
2.37^{\# \#}\end{array}$ & $\begin{array}{l}20.04 \pm \\
6.83 \triangle \triangle\end{array}$ \\
\hline HOMA-IR & $\begin{array}{l}2.63 \pm \\
0.84\end{array}$ & $\begin{array}{l}3.21 \pm \\
1.00\end{array}$ & $2.52 \pm 0.78$ & $\begin{array}{l}16.56 \pm \\
8.02^{\star *}\end{array}$ & $\begin{array}{l}9.22 \pm \\
2.25^{\# \#}\end{array}$ & $\begin{array}{l}18.42 \pm \\
5.23 \triangle \triangle\end{array}$ \\
\hline \multicolumn{7}{|c|}{ Lipid metabolism index } \\
\hline $\mathrm{TC}(\mathrm{mmol} / \mathrm{L})$ & $\begin{array}{l}2.44 \pm \\
0.65\end{array}$ & $\begin{array}{l}3.31 \pm \\
1.16\end{array}$ & $\begin{array}{l}1.80 \pm \\
0.51^{\#}\end{array}$ & $\begin{array}{l}4.67 \pm \\
1.21^{\text {*夫 }}\end{array}$ & $3.64 \pm 0.96^{\#}$ & $4.90 \pm 1.30^{\triangle}$ \\
\hline TG (mmol/L) & $\begin{array}{l}0.50 \pm \\
0.16\end{array}$ & $\begin{array}{l}0.60 \pm \\
0.14\end{array}$ & $\begin{array}{l}0.34 \pm \\
0.10^{\star \# \#}\end{array}$ & $\begin{array}{l}0.71 \pm \\
0.07^{\star \star}\end{array}$ & $\begin{array}{l}0.50 \pm \\
0.13^{\# \#}\end{array}$ & $0.58 \pm 0.15$ \\
\hline $\begin{array}{l}\text { LDL } \\
(\mathrm{mmol} / \mathrm{L})\end{array}$ & $\begin{array}{l}1.34 \pm \\
0.24\end{array}$ & $\begin{array}{l}1.89 \pm \\
0.31\end{array}$ & $\begin{array}{l}1.21 \pm \\
0.38^{\#}\end{array}$ & $\begin{array}{l}2.92 \pm \\
0.59^{* \star}\end{array}$ & $\begin{array}{l}2.03 \pm \\
0.64^{\# \#}\end{array}$ & $2.74 \pm 0.76^{\triangle}$ \\
\hline $\begin{array}{l}\mathrm{HDL} \\
(\mathrm{mmol} / \mathrm{L})\end{array}$ & $\begin{array}{l}1.30 \pm \\
0.14\end{array}$ & $\begin{array}{l}0.88 \pm \\
0.11^{\star \star}\end{array}$ & $\begin{array}{l}0.97 \pm \\
0.06^{\text {** }}\end{array}$ & $\begin{array}{l}0.79 \pm \\
0.13^{\text {** }}\end{array}$ & $0.80 \pm 0.18$ & $0.77 \pm 0.13$ \\
\hline $\begin{array}{l}\text { Note: Con: co } \\
\text { EDM + cheme } \\
\text { cholesterol; L } \\
\text { DM; } \triangle p<0.05 \text {, }\end{array}$ & $\begin{array}{l}\text { l; C: ch } \\
\text { reatme } \\
\text { low-der } \\
p<0.01\end{array}$ & $\begin{array}{l}\text { treatme } \\
\text { triglyce } \\
\text { oprotei } \\
\text { EDM }\end{array}$ & $\begin{array}{l}\text { exercise; } \\
\text { lC: total cl } \\
\text { lesterol. ** }\end{array}$ & $\begin{array}{l}\text { liabet } \\
\text { terol; } \\
\text { b1, DN } \\
\end{array}$ & $\begin{array}{l}\text { Is; EDM: exe } \\
\text { h-density lip } \\
{ }^{*} p<0.05,{ }^{\#}+\end{array}$ & $\begin{array}{l}\text { ised DM; EDC: } \\
\text { rotein } \\
.01, \text { EDM vs }\end{array}$ \\
\hline
\end{tabular}

Figure 5A showed liver gross specimen of mice, we found that 6-week exercise and exogenous chemerin treatment had no influence on the liver of normal mice; but exercise significantly alleviated fatty liver of DM mice (DM mice appeared pathological characteristic of fatty liver: big, yellow and oil), which was reversed by exogenous chemerin treatment. In addition, exercise-induced reduction in the liver weight of DM mice was reversed by exogenous chemerin treatment (Fig. 5B). As for liver oil red staining, Fig. 5C showed that a lot of lipid drops appeared in the liver of DM mice, and exercise significant decreased the amounts of lipid drops in the liver of DM mice, which was partly reversed by exogenous chemerin treatment.

Exogenous chemerin treatment reversed the exercise-induced reductions of serum chemerin and chemerin/CMKLR1 in the liver, gastrocnemius and fat of diabetes mice 
Not only serum chemerin but also the protein levels of chemerin in peripheral metabolic organs including liver, gastrocnemius and epididymal fat were increased significantly in DM mice (Fig. 6). After 6-week aerobic exercise, serum chemerin and the protein levels of chemerin in the metabolic organs (liver, gastrocnemius and epididymal fat) of EDM mice were decreased, which were reversed by exogenous chemerin treatment (but only a reversed trend in gastrocnemius). In Con mice, although exercise and exogenous chemerin treatment both had no obvious influence on serum chemerin and chemerin levels in the liver and gastrocnemius, exercise decreased and exogenous chemerin increased the level of chemerin in the epididymal fat.

For chemerin receptor CMKLR1, similar results were found in DM and Con mice. In DM mice, the protein levels of CMKLR1 in the liver, gastrocnemius and epididymal fat were increased, and 6-week aerobic exercise significantly reduced the levels of CMKLR1 in the liver, gastrocnemius and fat of DM mice, which were reversed by exogenous chemerin treatment (Fig. 6). In Con mice, exercise lowered and exogenous chemerin treatment enhanced CMKLR1 in epididymal fat, while no alteration was induced by the exercise or exogenous chemerin in the liver and gastrocnemius of Con mice.

\section{Exogenous chemerin treatment reversed exercise-induced increases of ATGL, LPL, GLUT4 and decrease of PEPCK in diabetes mice}

In Con mice, 6-week aerobic exercise increased the levels of ATGL (liver, gastrocnemius and epididymal fat), LPL (liver) and GLUT4 (gastrocnemius and epididymal fat), and exogenous chemerin treatment could decrease ATGL (liver and epididymal fat) and GLUT4 (gastrocnemius) of Con mice. For diabetes mice, 6-week aerobic exercise significantly increased the levels of ATGL, LPL (both in liver, gastrocnemius and epididymal fat) and GLUT4 (in gastrocnemius and epididymal fat) as well as decreased the levels of PEPCK (in liver) of DM mice, which were reversed by exogenous chemerin supplementation except for the LPL in epididymal fat and PEPCK in liver (only a trend) (Fig. 7). These results indicated that exercisedinduced changes of ATGL, LPL and GLUT4 in the peripheral metabolic organs of DM mice were mediated by the decreased chemerin.

\section{Exogenous chemerin treatment reversed exercise-induced increases of PPARY in the liver, gastrocnemius and epididymal fat of diabetes mice}

As shown in Fig. 8, 6-week of aerobic exercise significantly enhanced the protein levels of PPARy in the liver, gastrocnemius and epididymal fat of EDM mice, although aerobic exercise and exogenous chemerin treatment had no obvious influences on Con mice. Furthermore, exogenous chemerin supplementations reversed exercise-induced increases of PPARY in the liver and epididymal fat of EDC mice compared to EDM mice, while only a reversed trend of PPARY in the gastrocnemius of EDC mice. These results indicated that exercised-induced increase of PPARY in DM mice was mediated by the decreased chemerin.

\section{Discussion}




\section{Role of increased chemerin in the glycolipid metabolism disorder of diabetes}

Many clinical studies have clearly confirmed the important role of enhanced serum chemerin in the development of type 2 diabetes and the disorder of glucose metabolism in the patients with obesity and diabetes[40]. Furthermore, increased serum chemerin was positively correlated with multiple glucose metabolism parameters (including $\mathrm{HbA1}$ c, FBG, serum insulin and HOMA-IR) and lipid profile (including TC, TG and LDL) in the patients with obesity and obesity related diseases [41-44]. Besides serum chemerin, the increases of chemerin in the livers were demonstrated to exert a key role in glucose metabolism disorder of ob/ob mice and $\mathrm{db} / \mathrm{db}$ mice, and exogenous chemerin administration exacerbated glucose intolerance and decreased tissue glucose uptake in obese/diabetic mice[11]. In addition, studies have reported a close link between enhanced chemerin and IR (vital factor in the development of obesity), for example, excessive chemerin inhibited glucose intake and steatolysis of muscle tissue and lead to IR [45], and reducing the levels of serum chemerin in overweight, obese and type 2 diabetic patients would increase insulin sensitivity[46]. The vital role of chemerin/CMKLR1 in impairment of glycolipid metabolism including IR was demonstrated by chemerin or CMKLR1 knockout mice[47, 48], and CMKLR1 gene silencing improved cardiac dysfunction in diabetic cardiomyopathy rats[49].

Our previous study found similar results in diabetes rats, that up-regulation of serum chemerin and chemerin/CMKLR1 in metabolic organs was likely to be associated with the disorder of glycolipid metabolism in diabetes rats[10], and the present study extended the relationship of enhanced chemerin/CMKLR1 and glycolipid metabolism disorder from diabetes rats to diabetes mice, confirming the important role of chemerin/CMKLR1 in glycolipid metabolism disorder. These results are benefit to clarify adipokine and inflammatory cytokines (including chemerin) related mechanisms of diabetes.

\section{Exercise-induced decrease of chemerin in diabetes was involved in the improvement of glycolipid metabolism}

It has been widely accepted that aerobic exercise improved glycolipid metabolism of obesity and obesity related diseases[12, 13], but the mechanisms remain not fully clarified. An increasing evidences showed that serum chemerin in diabetes patients $[2,18-20]$ and chemerin/CMKLR1 in the peripheral metabolic organs of diabetes rats[10] were decreased by aerobic exercise, which was involved in exercise-induced improvements of glycolipid metabolism. In the present study, similar results were observed in diabetes mice, that 6-week aerobic exercise reduced serum chemerin concentration and the protein level of chemerin in peripheral metabolism organs (liver, gastrocnemius and epididymal fat), accompanied with the improvement of glycolipid metabolism. Furthermore, exogenous chemerin treatment (from the 3rd to 6th week of exercise intervention) reversed exercise-induced improvement of glycolipid metabolism in diabetes mice, which demonstrated the important role of decreased chemerin in exercise-induced improvement of glycolipid metabolism in diabetes mice. 
It is deserved to mention that numerous studies have reported a beneficial effect of weight loss and/or exercise training on chemerin levels, and the present study found no changes in the body weight and food intake of exercised diabetic mice, which suggested exercise alone could reduce the levels of chemerin in serum and metabolic organs of diabetes mice (in a weight loss-independent way).

\section{Decreased chemerin by exercise improved glycolipid metabolism of diabetes mice through up-regulating key enzymes and protein (ATGL, LPL and GLUT4) mediated by PPARY}

It has been reported that exercise up-regulated the protein levels of ATGL[50, 51] and LPL[26] in skeletal muscle. Besides, exercise also promoted the expression of ATGL in adipose tissue, which promoted fat metabolism and facilitated conversion of TG into FFA; whereas exercise-induced increases of expression and activity of LPL in skeletal muscle and plasma could reduce the levels of plasma insulin and blood glucose and improve lipid metabolism $[52,53]$. In addition, exercise could decrease PEPCK protein level in the liver of HFD-induced obese mice, thus inhibiting endogenous glucose production and subsequently improving IR[54]; and aerobic exercise increased the level of GLUT4 in skeletal muscle of exercised rats, thus promoting glucose uptake in skeletal muscle and speeding up the clearance of glucose[55]. Similar results were found in the present study, that exercise increased the protein levels of ATGL and LPL in the liver and gastrocnemius while decreased PEPCK in diabetic rats and diabetic mice, and GLUT4 in the gastrocnemius and adipose of diabetes mice was detected and showed an increase by exercise, accompanied with exercise-induced improvement of glycolipid metabolism and lowered levels of chemerin in serum and peripheral metabolism organs. More importantly, exogenous chemerin treatment reversed the increases of ATGL, LPL and GLUT4 but not the decrease of PEPCK in diabetes mice, and simultaneously reversed partly exercise-induced improvement of glycolipid metabolism in diabetes mice. These results demonstrated that the effect of decreased chemerin on exercise-induced improvement of glycolipid metabolism in diabetes was fulfilled through increasing metabolism key enzymes (ATGL, LPL) and key protein GLUT4 in peripheral metabolic organs.

The specific links of ATGL, LPL, GLUT4 and PEPCK with chemerin remain unclear. Limit literatures mainly reported in vitro experiment results. For example, the expression of chemerin was decreased during lipolysis while LPL level was increased in cultured bovine mature adipocytes. Exogenous chemerin treatment decreased the mRNA level of LPL in mature adipocytes on 8th day post-intervention[38] and in goat intramuscular preadipocyte[56], and greatly changed the mRNA levels of ATGL in mature adipocytes[57]. The modulation of CMKLR1 on GLUT4 was reported in CMKLR1 knockout mice fed with HFD, representing reduced GLUT4 protein level compared to wild-type mice[48]. The present study extended the regulatory effects of chemerin on ATGL, LPL, PEPCK and GLUT4 from in vitro to in vivo level, and further indicated that the decreased chemerin by exercise exerted its improved role in glycolipid metabolism through increasing the levels of ATGL, LPL and GLUT4 in diabetes mice.

How decreased chemerin by exercise resulted in the increases of key metabolic enzymes and protein (such as ATGL, LPL, PEPCK and GLUT4) in the peripheral metabolic organs of diabetes mice? Until now, researches on this issue are rarely reported. Considering ATGL, LPL, PEPCK and GLUT4 are regulated by 
PPARy, and the important roles of PPARy in regulating glycolipid metabolism[30, 31] as well as the interaction between chemerin and PPARY in vitro[36-38], we speculated that the modulations of decreased chemerin on exercise-induced changes of ATGL, LPL, PEPCK and GLUT4 were mediated by upregulating PPARY. To verify our speculation, two main studies in diabetes rats and diabetes mice were completed, and we found that: (1) in diabetes rats, exercise-induced alterations of ATGL, LPL and PEPCK were reversed by PPARY inhibitor GW9662 and further strengthened by PPARY agonist pioglitazone; (2) in diabetes mice, exogenous chemerin treatment reversed exercise-induced alterations of PPARY, ATGL, LPL and GLUT4 (but not PEPCK) in the liver, gastrocnemius and fat. These results indicated that the decrease of chemerin by exercise increased key metabolic enzymes and protein (ATGL, LPL and GLUT4) in diabetes through up-regulating PPARY.

It is interesting about the relationship between chemerin and PPARy. Firstly, chemerin was reported to be a target gene of PPARY in vitro in promoting mesenchymal stem cell adipogenesis[36], and PPARY agonist reduced chemerin expression in adipose tissue and inhibited chemerin secretion from adipocytes by more than $80 \%[37]$. Our previous work also reported that in vivo, exercise-induced decrements of chemerin/CMKLR1 were mediated by PPARY in diabetic rats[10]. Then, other literatures reported that in vitro chemerin promoted preadipocyte differentiation and maturation by up-regulating the levels of PPARy [36, 38], and the present study indicated the regulation of chemerin on PPARy in diabetes mice in vivo. The interaction between chemerin and PPARY and its biological significances deserve further study in future.

\section{Conclusions}

The present study demonstrated that the decreased chemerin played important roles in exercise-induced improvements of glycolipid metabolism and fatty liver in diabetes, through increasing glycolipid metabolism key enzymes and protein (ATGL, LPL and GLUT4) in peripheral metabolic organs mediated by PPARY.

\section{Abbreviations}

CMKLR1: chemerin receptor chemokine-like receptor; PPARY: peroxisome proliferator activated receptor $\gamma_{\text {; }}$ ATGL: adipose triglyceride lipase; LPL: lipoprotein lipase; GLUT4: glucose transporter 4; PEPCK: phosphoenolpyruvate carboxykinase; HFD: high fat diet; STZ: streptozotocin; FBG: fasting blood glucose; TG: triglyceride; TC: total cholesterol; HDL: high-density lipoprotein cholesterol; LDL: low-density lipoprotein cholesterol; FINS: fasting insulin; HOMA-IR: homeostasis model assessment of insulin resistance.

\section{Declarations}

\section{Ethics approval}


The animal protocol was approved and the experiments were supervised by the Ethics Committee of Shanghai University of Sport (Approval number: 2018009).

\section{Consent for publication}

No applicable

\section{Availability of data and materials}

The datasets used during the present study are available from the corresponding author upon reasonable request.

\section{Founding}

This work is supported by grants from the National Natural Science Foundation of China (No.31872801) and from Shanghai Key Lab of Human Performance (Shanghai University of Sport) (No. 11DZ2261100).

\section{Authors' contributions}

Xiaohui Wang, design the experiments as well as revised the manuscript; Xiaojing Lin performed experiments, analyzed data, made picture and drafted manuscript; Lijun Yin, participate in intraperitoneally injection of chemerin and aerobic exercise intervention in mice; Jing Qu, participate in the detection of body composition and body weight of mice and aerobic exercise intervention in mice.

\section{Acknowledgments}

The authors gratefully acknowledge the grants for National Natural Science Foundation of China (No.31872801) and Shanghai Key Lab of Human Performance (Shanghai University of Sport) (No. 11DZ2261100).

\section{Competing interests}

The authors declare that they have no conflict of interest.

\section{References}

1. Zylla S, Pietzner M, Kuhn JP, Volzke H, Dorr M, Nauck M, Friedrich N. Serum chemerin is associated with inflammatory and metabolic parameters-results of a population-based study. Obesity (Silver Spring). 2017; 25:468-475.

2. Liu M, Lin X, Wang X. Decrease in serum chemerin through aerobic exercise plus dieting and its association with mitigation of cardio-metabolic risk in obese female adolescents. J Pediatr Endocrinol Metab. 2018; 31:127-135.

3. Gu P, Wang W, Yao Y, Xu Y, Wang L, Zang P, Ma J, Yang C, Liang J, Lu B, Shao J. Increased Circulating Chemerin in Relation to Chronic Microvascular Complications in Patients with Type 2 Diabetes. Int $J$ 
Endocrinol. 2019; 2019:8693516.

4. Lachine NA, Elnekiedy AA, Megallaa MH, Khalil GI, Sadaka MA, Rohoma KH, Kassab HS. Serum chemerin and high-sensitivity $C$ reactive protein as markers of subclinical atherosclerosis in Egyptian patients with type 2 diabetes. Ther Adv Endocrinol Metab. 2016; 7:47-56.

5. Li Y, Shi B, Li S. Association between serum chemerin concentrations and clinical indices in obesity or metabolic syndrome: a meta-analysis. PLoS One. 2014; 9:e113915.

6. Eichelmann F, Schulze MB, Wittenbecher C, Menzel J, Weikert C, di Giuseppe R, Biemann R, Isermann $\mathrm{B}$, Fritsche $\mathrm{A}$, Boeing $\mathrm{H}$, Aleksandrova K. Chemerin as a Biomarker Linking Inflammation and Cardiovascular Diseases. J Am Coll Cardiol. 2019; 73:378-379.

7. Hamza RT, Elkabbany ZA, Shedid AM, Hamed Al, Ebrahim AO. Serum Chemerin in Obese Children and Adolescents Before and After L-Carnitine Therapy: Relation to Nonalcoholic Fatty Liver Disease and Other Features of Metabolic Syndrome. Arch Med Res. 2016; 47:541-549.

8. Gasbarrino K, Mantzoros C, Gorgui J, Veinot JP, Lai C, Daskalopoulou SS. Circulating Chemerin Is Associated With Carotid Plaque Instability, Whereas Resistin Is Related to Cerebrovascular Symptomatology. Arterioscler Thromb Vasc Biol. 2016; 36:1670-1678.

9. Yang J, Ao N, Du J, Wang X, He Y. Protective effect of liraglutide against ER stress in the liver of highfat diet-induced insulin-resistant rats. Endocrine. 2015; 49:106-118.

10. Lin X, Yang Y, Qu J, Wang X. Aerobic exercise decreases chemerin/CMKLR1 in the serum and peripheral metabolic organs of obesity and diabetes rats by increasing PPARgamma. Nutr Metab (Lond). 2019;16:17.

11. Ernst MC, Issa M, Goralski KB, Sinal CJ. Chemerin exacerbates glucose intolerance in mouse models of obesity and diabetes. Endocrinology. 2010; 151:1998-2007.

12. M. A. Nimmo ML, J.L.Viana, J.A.King. The effect of physical activity on mediators of inflammation. Diabetes Obes Metab. 2013; 15:51-60.

13. Hayashino Y, Jackson JL, Hirata T, Fukumori N, Nakamura F, Fukuhara S, Tsujii S, Ishii H. Effects of exercise on C-reactive protein, inflammatory cytokine and adipokine in patients with type 2 diabetes: A meta-analysis of randomized controlled trials. Metabolism-Clinical and Experimental. 2014; 63:431-440.

14. Wiklund P, Alen M, Munukka E, Cheng SM, Yu B, Pekkala S, S C. Metabolic response to 6-week aerobic exercise training and dieting in previously sedentary overweight and obese pre-menopausal women: A randomized trial. J Sport Health Sci. 2014;217-224.

15. Lin XJ, Yin L, Wang XH. Decrease of circulatory level of inflammatory factor Lp-PLA2 by short-term aerobic exercise in obese female juveniles. Adaptive Medicine. 2016; 8:6-11.

16. Otten J, Andersson J, Stahl J, Stomby A, Saleh A, Waling M, Ryberg M, Hauksson J, Svensson M, Johansson B, Olsson T. Exercise Training Adds Cardiometabolic Benefits of a Paleolithic Diet in Type 2 Diabetes Mellitus. J Am Heart Assoc. 2019; 8:e010634.

17. Rech A, Botton CE, Lopez P, Quincozes-Santos A, Umpierre D, Pinto RS. Effects of short-term resistance training on endothelial function and inflammation markers in elderly patients with type 2 
diabetes: A randomized controlled trial. Exp Gerontol. 2019; 118:19-25.

18. Venojarvi M, Wasenius N, Manderoos S, Heinonen OJ, Hernelahti M, Lindholm H, Surakka J, Lindstrom J, Aunola S, Atalay M, Eriksson JG. Nordic walking decreased circulating chemerin and leptin concentrations in middle-aged men with impaired glucose regulation. Ann Med. 2013; 45:162170.

19. Neuparth MJ, Proenca JB, Santos-Silva A, Coimbra S. The positive effect of moderate walking exercise on chemerin levels in Portuguese patients with type 2 diabetes mellitus. J Investig Med. $2014 ; 62: 350-353$.

20. Stefanov T, Bluher M, Vekova A, Bonova I, Tzvetkov S, Kurktschiev D, Temelkova-Kurktschiev T. Circulating chemerin decreases in response to a combined strength and endurance training. Endocrine. 2014; 45:382-391.

21. Malin SK, Navaneethan SD, Mulya A, Huang H, Kirwan JP. Exercise-induced lowering of chemerin is associated with reduced cardiometabolic risk and glucose-stimulated insulin secretion in older adults. J Nutr Health Aging. 2014; 18:608-615.

22. Chakaroun R, Raschpichler M, Kloting N, Oberbach A, Flehmig G, Kern M, Schon MR, Shang E, Lohmann T, Dressler M. Effects of weight loss and exercise on chemerin serum concentrations and adipose tissue expression in human obesity. Metabolism. 2012; 61:706-714.

23. Kim SH, Lee SH, Ahn KY, Lee DH, Suh YJ, Cho SG, Choi YJ, Lee SY, Hong SB, Kim YS. Effect of lifestyle modification on serum chemerin concentration and its association with insulin sensitivity in overweight and obese adults with type 2 diabetes. Clin Endocrinol (Oxf). 2014; 80:825-833.

24. Zhang W, Bu SY, Mashek MT, I OS, Sibai Z, Khan SA, Ilkayeva O, Newgard CB, Mashek DG, Unterman TG. Integrated Regulation of Hepatic Lipid and Glucose Metabolism by Adipose Triacylglycerol Lipase and FoxO Proteins. Cell Rep. 2016; 15:349-359.

25. Makoveichuk E, Vorrsjo E, Olivecrona T, Olivecrona G. TNF-alpha decreases lipoprotein lipase activity in 3T3-L1 adipocytes by up-regulation of angiopoietin-like protein 4. Biochim Biophys Acta. 2017; 1862:533-540.

26. Kersten S. Physiological regulation of lipoprotein lipase. Biochim Biophys Acta. 2014; 1841:919-933.

27. Stark R, Guebre-Egziabher F, Zhao X, Feriod C, Dong J, Alves TC, loja S, Pongratz RL, Bhanot S, Roden M. A role for mitochondrial phosphoenolpyruvate carboxykinase (PEPCK-M) in the regulation of hepatic gluconeogenesis. J Biol Chem. 2014; 289:7257-7263.

28. Brumfield A, Chaudhary N, Molle D, Wen J, Graumann J, McGraw TE. Insulin-promoted mobilization of GLUT4 from a perinuclear storage site requires RAB10. Mol Biol Cell. 2021; 32:57-73.

29. Saori Mukaida, Masaaki Sato, Anette I Öberg, Nodi Dehvari, Jessica M Olsen, Martina Kocan, Michelle Louise Halls, Jon Merlin, Anna L Sandström, Robert I Csikasz, Bronwyn Anne Evans, Roger James Summers, Dana Sabine Hutchinson, Tore Bengtsson. BRL37344 stimulates GLUT4 translocation and glucose uptake in skeletal muscle via $\beta$ 2-adrenoceptors without causing classical receptor desensitization. Am J Physiol Regul Integr Comp Physiol. 2019; 316:R666-R677. 
30. Lefterova MI, Haakonsson AK, Lazar MA, Mandrup S. PPARgamma and the global map of adipogenesis and beyond. Trends Endocrinol Metab. 2014; 25:293-302.

31. Wang S, Dougherty EJ, Danner RL. PPARgamma signaling and emerging opportunities for improved therapeutics. Pharmacol Res. 2016; 111:76-85.

32. Houshmand G, Mansouri MT, Naghizadeh B, Hemmati AA, Hashemitabar M. Potentiation of indomethacin-induced anti-inflammatory response by pioglitazone in carrageenan-induced acute inflammation in rats: Role of PPARgamma receptors. Int Immunopharmacol. 2016; 38:434-442.

33. Ruffino JS, Davies NA, Morris K, Ludgate M, Zhang L, Webb R, Thomas AW. Moderate-intensity exercise alters markers of alternative activation in circulating monocytes in females: a putative role for PPARgamma. Eur J Appl Physiol. 2016; 116:1671-1682.

34. Kapravelou G, Martinez R, Andrade AM, Nebot E, Camiletti-Moiron D, Aparicio VA, Lopez-Jurado M, Aranda P, Arrebola F, Fernandez-Segura E. Aerobic interval exercise improves parameters of nonalcoholic fatty liver disease (NAFLD) and other alterations of metabolic syndrome in obese Zucker rats. Appl Physiol Nutr Metab. 2015; 40:1242-1252.

35. Kim JC. The effect of exercise training combined with PPARgamma agonist on skeletal muscle glucose uptake and insulin sensitivity in induced diabetic obese Zucker rats. J Exerc Nutrition Biochem. 2016; 20:42-50.

36. Muruganandan S, Parlee SD, Rourke JL, Ernst MC, Goralski KB, Sinal CJ. Chemerin, a novel peroxisome proliferator-activated receptor gamma (PPARgamma) target gene that promotes mesenchymal stem cell adipogenesis. J Biol Chem. 2011; 286:23982-23995.

37. Sell H, Laurencikiene J, Taube A, Eckardt K, Cramer A, Horrighs A, Arner P, Eckel J. Chemerin is a novel adipocyte-derived factor inducing insulin resistance in primary human skeletal muscle cells. Diabetes. 2009; 58:2731-2740.

38. Fu YY, Chen KL, Li HX, Zhou GH. The adipokine Chemerin induces lipolysis and adipogenesis in bovine intramuscular adipocytes. Mol Cell Biochem. 2016; 418:39-48.

39. Yin Y, Hao H, Cheng Y, Zang L, Liu J, Gao J, Xue J, Xie Z, Zhang Q, Han W, Mu Y. Human umbilical cord-derived mesenchymal stem cells direct macrophage polarization to alleviate pancreatic islets dysfunction in type 2 diabetic mice. Cell Death Dis. 2018; 9:760.

40. Weigert J, Neumeier M, Wanninger J, Filarsky M, Bauer S, Wiest R, Farkas S, Scherer MN, Schaffler A, Aslanidis $C$. Systemic chemerin is related to inflammation rather than obesity in type 2 diabetes. Clin Endocrinol (Oxf). 2010; 72:342-348.

41. Salama FE, Anass QA, Abdelrahman AA, Saeed EB. Chemerin: A biomarker for cardiovascular disease in diabetic chronic kidney disease patients. Saudi J Kidney Dis Transpl. 2016; 27:977-984.

42. El-Deeb TS, Bakkar SM, Eltoony L, Zakhary MM, Kamel AA, Nafee AM, Hetta HF. The adipokine Chemerin and Fetuin-A Serum Levels in Type 2 Diabetes Mellitus: Relation to Obesity and Inflammatory Markers. Egypt J Immunol. 2018; 25:191-202.

43. Hah YJ, Kim NK, Kim MK, Kim HS, Hur SH, Yoon HJ, Kim YN, Park KG. Relationship between Chemerin Levels and Cardiometabolic Parameters and Degree of Coronary Stenosis in Korean 
Patients with Coronary Artery Disease. Diabetes Metab J. 2011; 35:248-254.

44. Lu B, Zhao M, Jiang W, Ma J, Yang C, Shao J, Gu P. Independent Association of Circulating Level of Chemerin With Functional and Early Morphological Vascular Changes in Newly Diagnosed Type 2 Diabetic Patients. Medicine (Baltimore). 2015; 94:e1990.

45. Goralski KB, McCarthy TC, Hanniman EA, Zabel BA, Butcher EC, Parlee SD, Muruganandan S, Sinal CJ. Chemerin, a novel adipokine that regulates adipogenesis and adipocyte metabolism. J Biol Chem. 2007; 282:28175-28188.

46. Kim SH, Lee SH, Ahn KY, Lee DH, Suh YJ, Cho SG, Choi YJ, Lee DH, Lee SY, Hong SB. Effect of lifestyle modification on serum chemerin concentration and its association with insulin sensitivity in overweight and obese adults with type 2 diabetes. Clin Endocrinol (Oxf). 2014; 80:825-833.

47. Takahashi M, Okimura Y, Iguchi G, Nishizawa H, Yamamoto M, Suda K, Kitazawa R, Fujimoto W, Takahashi K, Zolotaryov FN. Chemerin regulates beta-cell function in mice. Sci Rep. 2011; 1:123.

48. Ernst MC, Haidl ID, Zuniga LA, Dranse HJ, Rourke JL, Zabel BA, Butcher EC, Sinal CJ. Disruption of the chemokine-like receptor-1 (CMKLR1) gene is associated with reduced adiposity and glucose intolerance. Endocrinology. 2012; 153:672-682.

49. Xie Y, Huang Y, Ling X, Qin H, Wang M, Luo B. Chemerin/CMKLR1 Axis Promotes Inflammation and Pyroptosis by Activating NLRP3 Inflammasome in Diabetic Cardiomyopathy Rat. Front Physiol. 2020; $11: 381$.

50. Wang H, Astarita G, Taussig MD, Bharadwaj KG, DiPatrizio NV, Nave KA, Piomelli D, Goldberg IJ, Eckel $\mathrm{RH}$. Deficiency of lipoprotein lipase in neurons modifies the regulation of energy balance and leads to obesity. Cell Metab. 2011; 13:105-113.

51. Alsted TJ, Nybo L, Schweiger M, Fledelius C, Jacobsen P, Zimmermann R, Zechner R, Kiens B. Adipose triglyceride lipase in human skeletal muscle is upregulated by exercise training. Am $\mathrm{J}$ Physiol Endocrinol Metab. 2009; 296:E445-453.

52. Van Hall G. The Physiological Regulation of Skeletal Muscle Fatty Acid Supply and Oxidation During Moderate-Intensity Exercise. Sports Med. 2015; 45 Suppl 1:S23-32.

53. Sasaki T, Nakata R, Inoue H, Shimizu M, Inoue J, Sato R. Role of AMPK and PPARgamma1 in exercise-induced lipoprotein lipase in skeletal muscle. Am J Physiol Endocrinol Metab.2014; 306:E1085-1092.

54. Chen N, Cheng JB, Zhou LM, Lei T, Chen LH, Shen Q, Qin LQ, Wan ZX. Effects of treadmill running and rutin on lipolytic signaling pathways and TRPV4 protein expression in the adipose tissue of dietinduced obese mice. Journal of Physiology and Biochemistry. 2015; 71:733-742.

55. Munoz VR, Gaspar RC, Kuga GK, da Rocha AL, Crisol BM, Botezelli JD, Baptista IL, Mekary RA, da Silva ASR, Cintra DE. Exercise increases Rho-kinase activity and insulin signaling in skeletal muscle. J Cell Physiol. 2018; 233(6):4791-4800.

56. Ma J, Liao H, Lin Y, Huang K, Zhu J, Wang Y. Molecular characterization, expression analysis of Chemerin gene and its potential role in intramuscular adipocyte differentiation of goat. Anim Biotechnol. 2020; 31:382-390. 
57. Fu YY, Hu BH, Chen KL, Li HX. Chemerin induces lipolysis through ERK1/2 pathway in intramuscular mature adipocytes of dairy bull calves. J Cell Biochem. 2018.

\section{Figures}

A
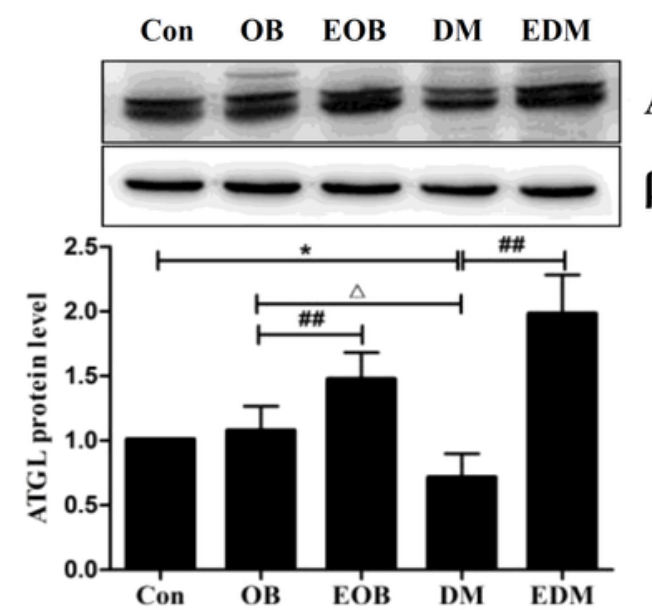

Con OB EOB DM EDM
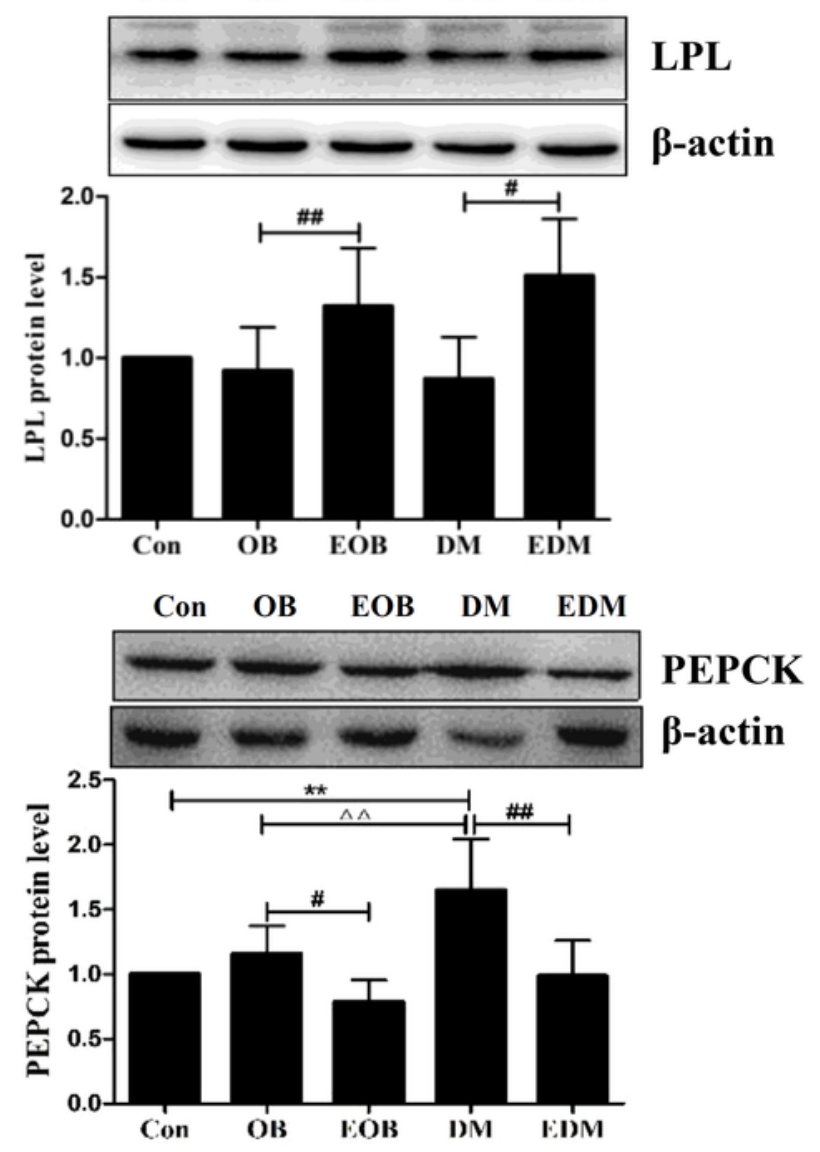

B

ATGL

$\beta$-actin

LPL

$\beta$-actin

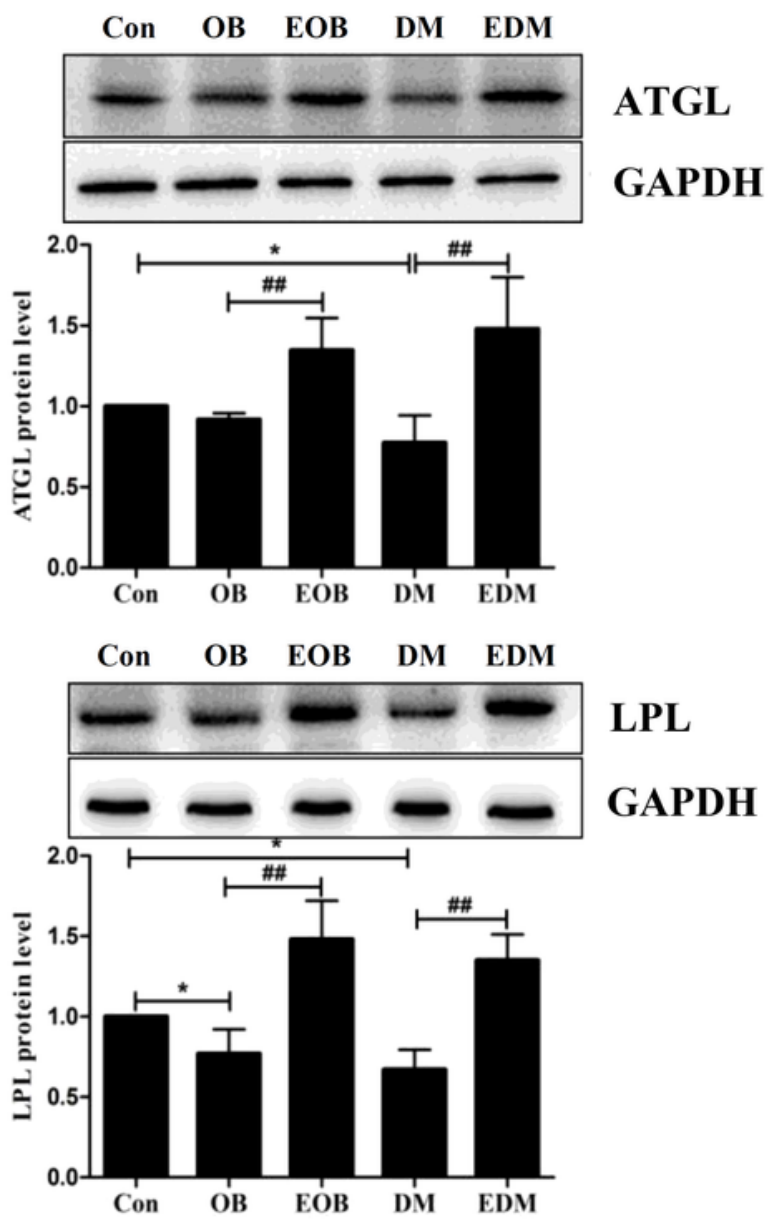

ATGL

GAPDH

LPL

GAPDH

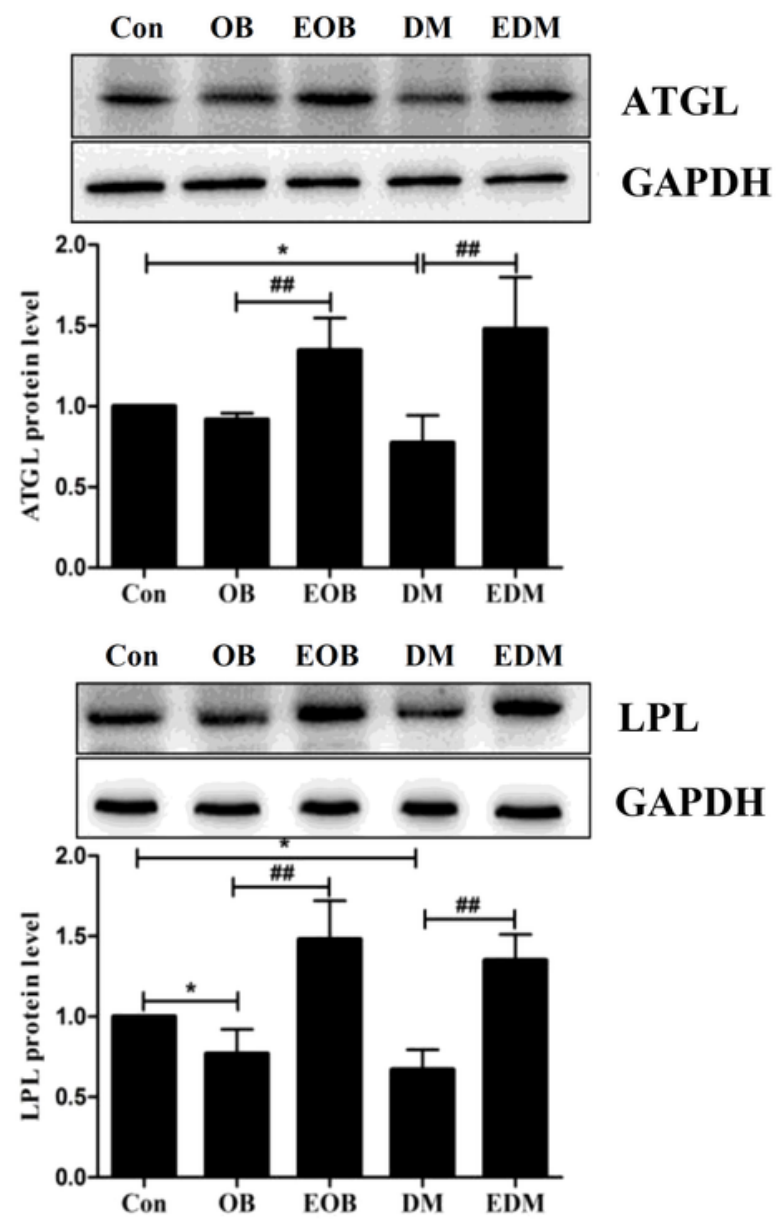

Figure 1 
The protein levels of ATGL, LPL and PEPCK were significantly changed by 4-week exercise in the liver (A) and gastrocnemius (B) in diabetic rats. The levels of ATGL and LPL in the livers and gastrocnemius were up-regulated, and PEPCK in the livers was down-regulated by 4-week aerobic exercise in DM and OB rats. The blots of ATGL, LPL and PEPCK were quantified by Tanon software and normalized against $\beta$-actin or GAPDH, then the normalized numbers were compared between different groups. Con: control; OB: obesity; EOB: exercised OB; DM: diabetes mellitus; EDM: exercised DM. *Pख0.05, **P囚0.01 vs Con; \#Pख0.05, \#\#Pख0.01 EOB vs OB or EDM vs DM; $\triangle \mathrm{P} \llbracket 0.05 \mathrm{DM}$ vs OB.

A
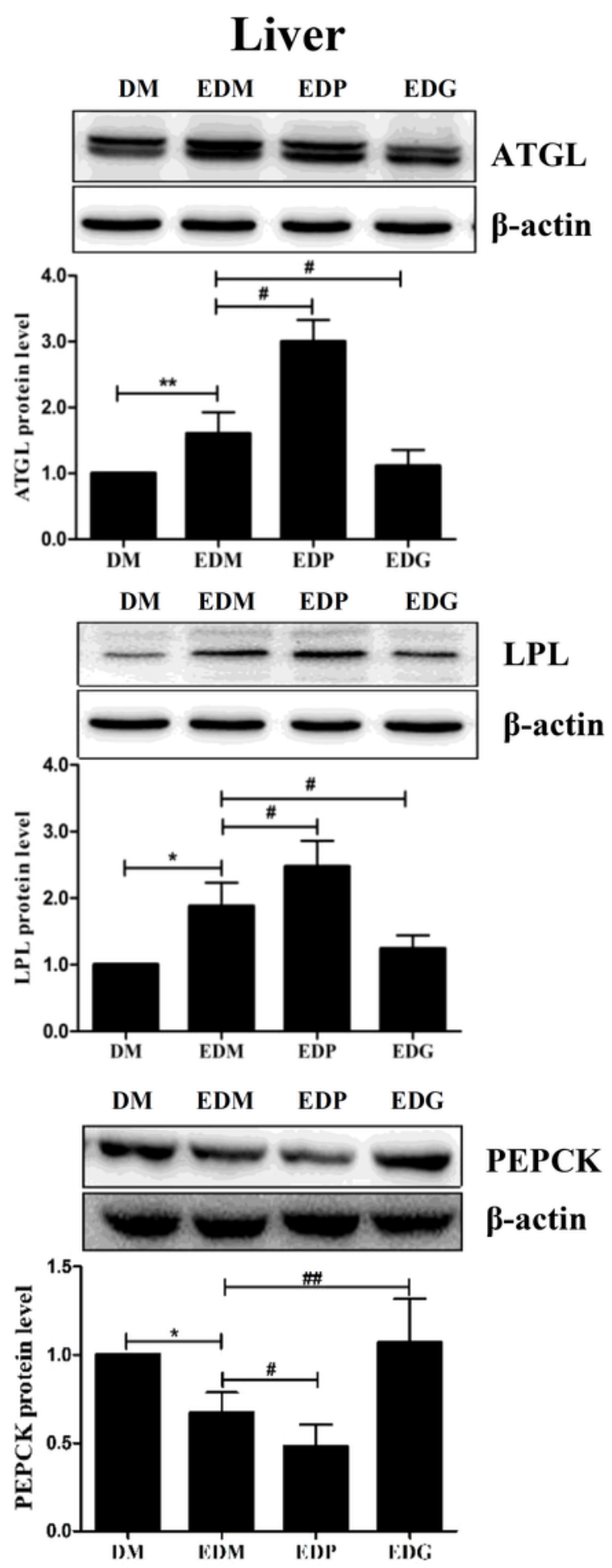

PEPCK

$\beta$-actin
B
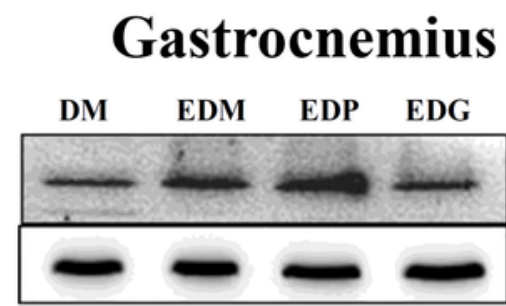

ATGL

GAPDH
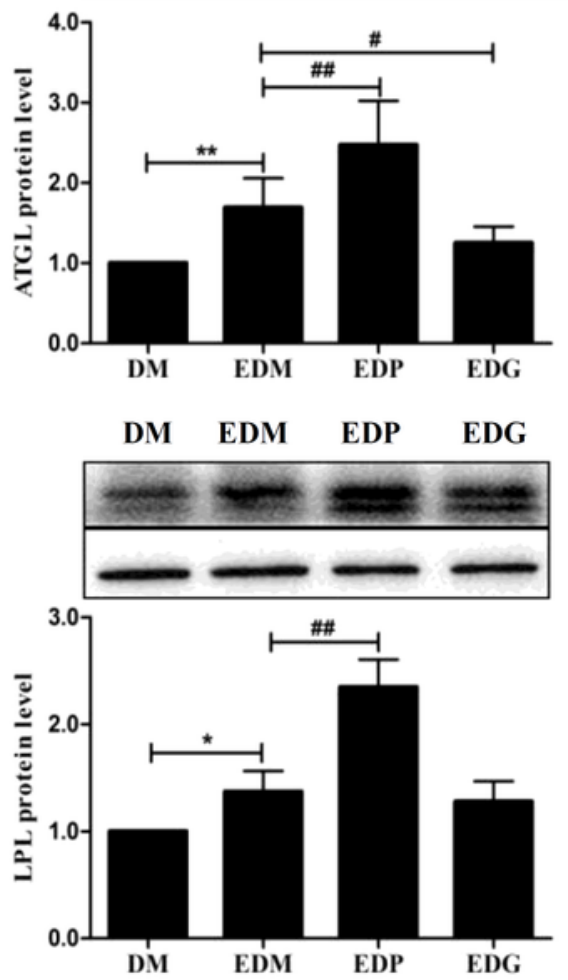

LPL

GAPDH 
Figure 2

Changes of ATGL, LPL and PEPCK in the liver (A) and gastrocnemius (B) of exercise diabetes rats were reversed by PPARY antagonist and further strengthened by PPARY agonist. The exercise-induced changes of ATGL (livers and gastrocnemius), LPL (only livers) and PEPCK (livers) at protein levels in EDM rats were reversed by PPARY antagonist GW9662, and further strengthened by PPARY agonist pioglitazone. The blots of ATGL and LPL were quantified by Tanon software and normalized against $\beta$-actin or GAPDH, then the normalized numbers were compared between different groups. DM: diabetes mellitus; EDM: exercised DM; EDP: exercised DM + pioglitazone; EDG: exercised DM + GW9662. *Pख0.05, **Pख0.01 vs DM. \#Pஐ0.05, \#\#Pख0.01 vs EDM.

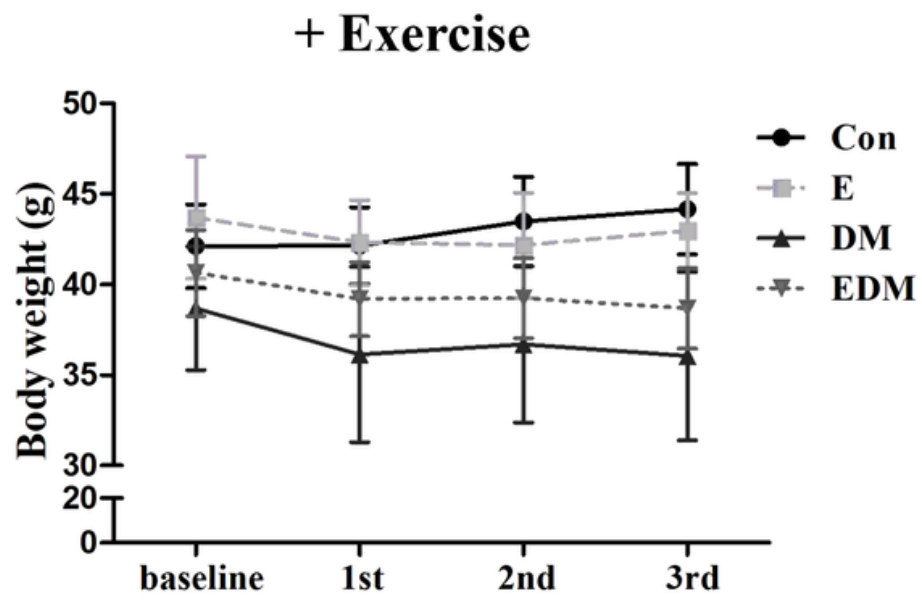

\section{+ Exercise + chemerin}

Time (w)

Figure 3

No influences of exogenous chemerin treatment on the body weight of exercised diabetic mice. Con: control; C: chemerin treatment; E: exercise; DM: diabetes mellitus; EDM: exercised DM; EDC: EDM + chemerin treatment.

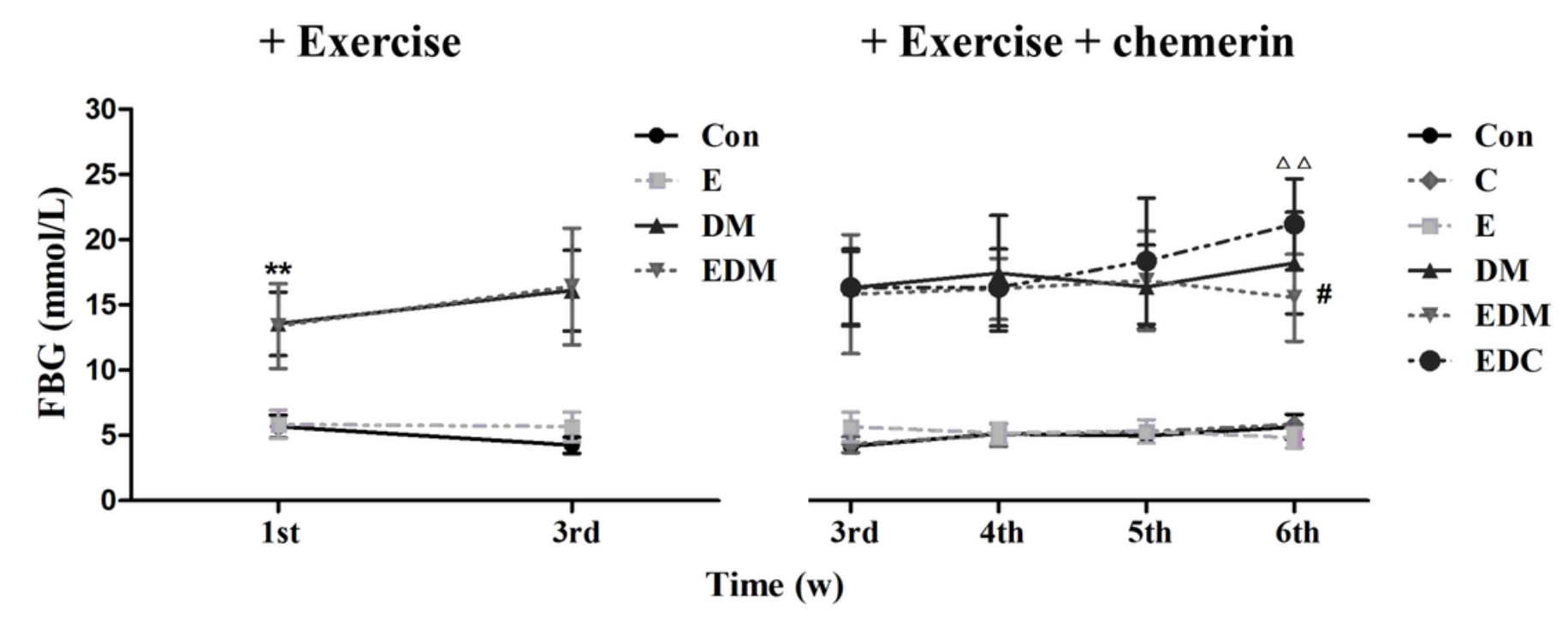




\section{Figure 4}

Effects of exogenous chemerin treatment on the levels of FBG of exercised diabetes mice. At 6th week of exercise intervention, exogenous chemerin treatment reversed the exercise-induced decrease of FBG in diabetic mice. Con: control; C: chemerin treatment; E: exercise; DM: diabetes mellitus; EDM: exercised DM; EDC: EDM + chemerin treatment. \#Pख0.05, EDM vs DM; $\triangle \triangle P \otimes 0.01, E D C$ vs EDM.

A

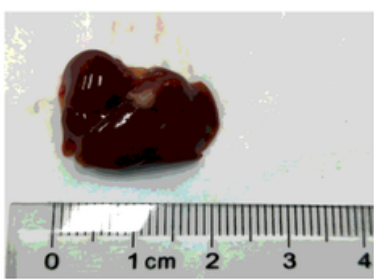

Con

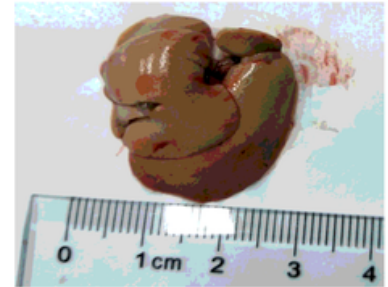

DM

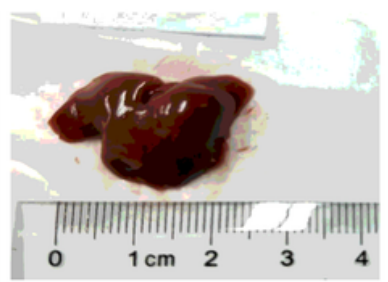

C

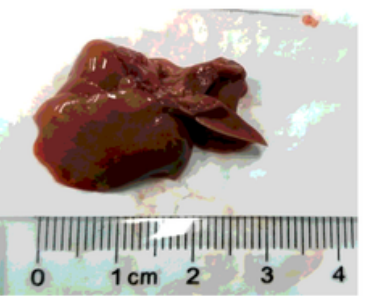

EDM

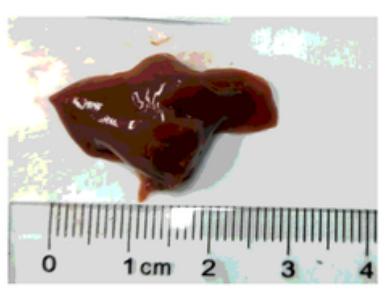

E

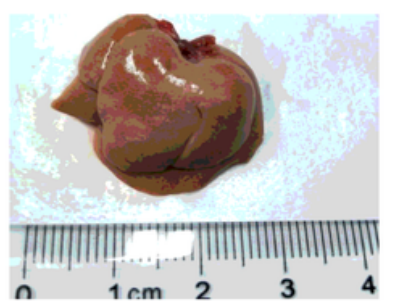

EDC
B

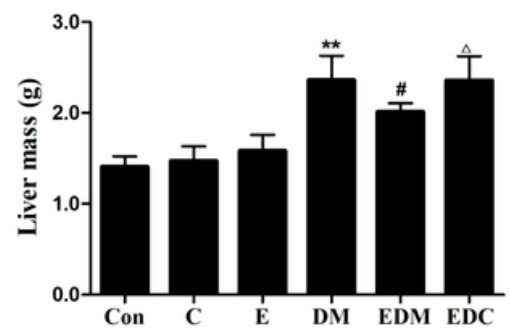

\section{C}

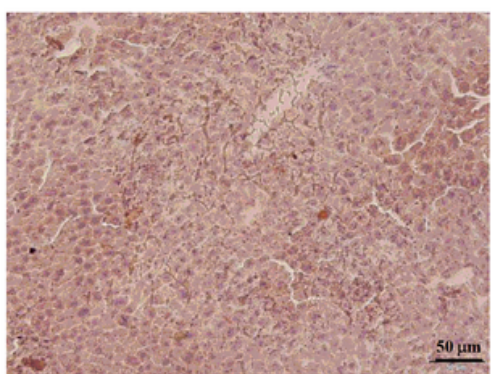

Con

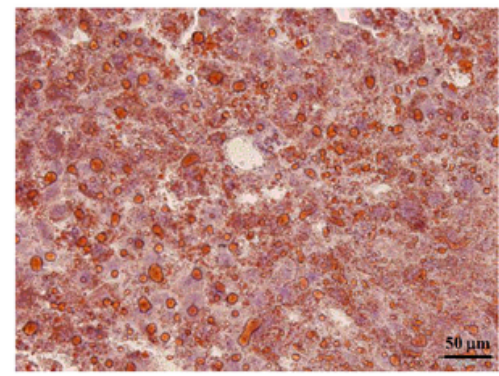

DM

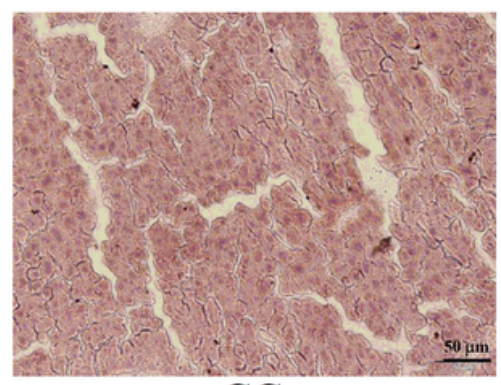

CC

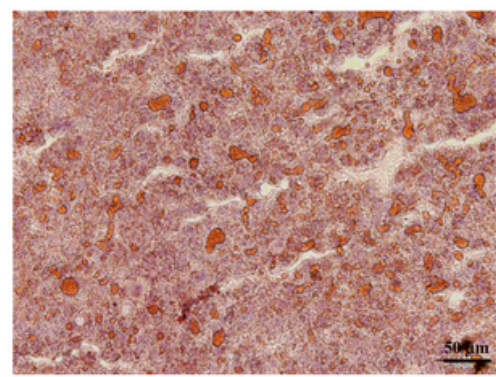

EDM

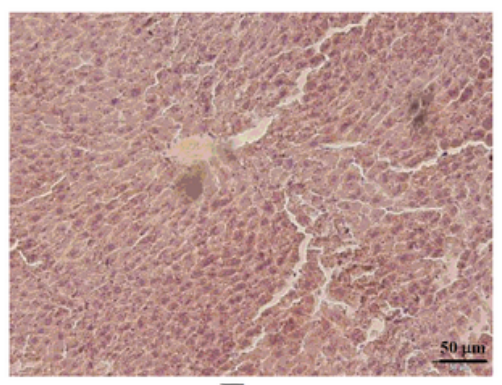

E

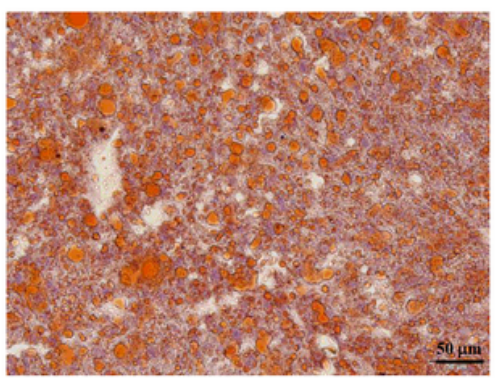

EDC

\section{Figure 5}

Effects of exogenous chemerin treatment on fatty liver from gross specimen (A), liver weights (B) and oil red staining (C) (400x) of exercised diabetes mice. Con: control; C: chemerin treatment; E: exercise; DM: 
diabetes mellitus; EDM: exercised DM; EDC: EDM + chemerin treatment. **P冈0.01, vs Con; \#P囚0.05, EDM vs DM; $\triangle \mathrm{P} \otimes 0.05, \mathrm{EDC}$ vs EDM.

A Serum

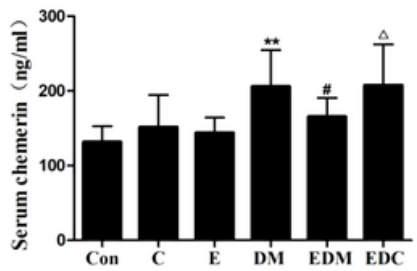

B

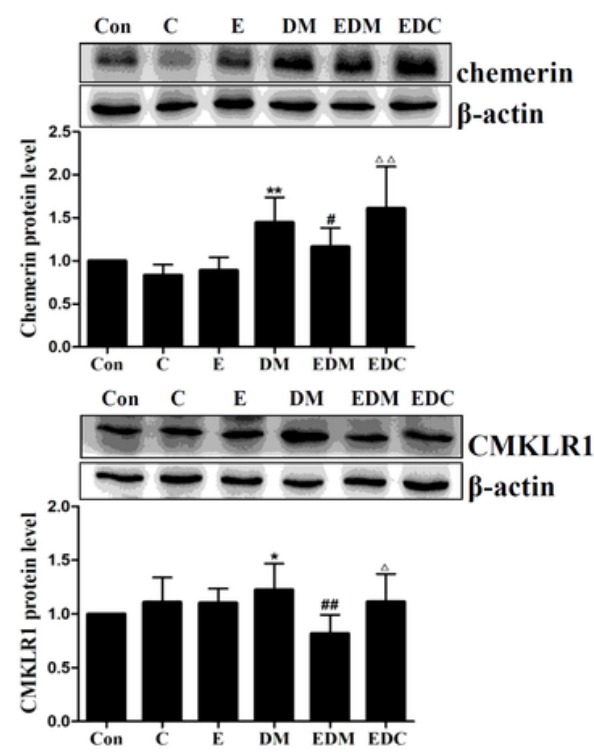

C
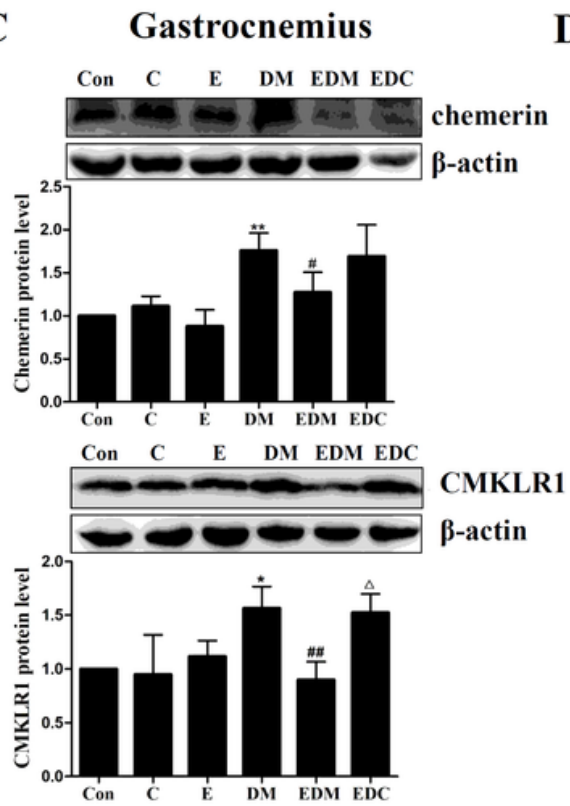

D Epididymal fat

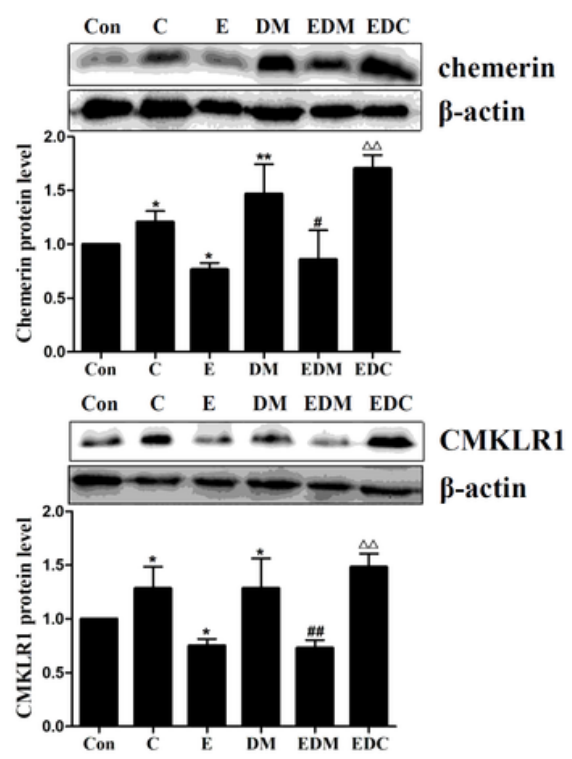

Figure 6

Effects of exogenous chemerin treatment on serum chemerin concentration $(A)$ and the protein levels of chemerin and CMKLR1 in the liver (B), gastrocnemius (C) and epididymal fat (D) of exercised diabetes mice. The blots of chemerin and CMKLR1 were quantified by Tanon software and normalized against $\beta$ actin, then the normalized numbers were compared and statistically analyzed (bottom). CMKLR1: chemokine-like receptor 1; Con: control; C: chemerin treatment; E: exercise; DM: diabetes mellitus; EDM:

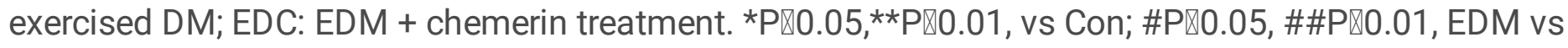
DM; $\triangle \mathrm{P} \otimes 0.05, \triangle \triangle \mathrm{P} \otimes 0.01, \mathrm{EDC}$ vs EDM. 
A
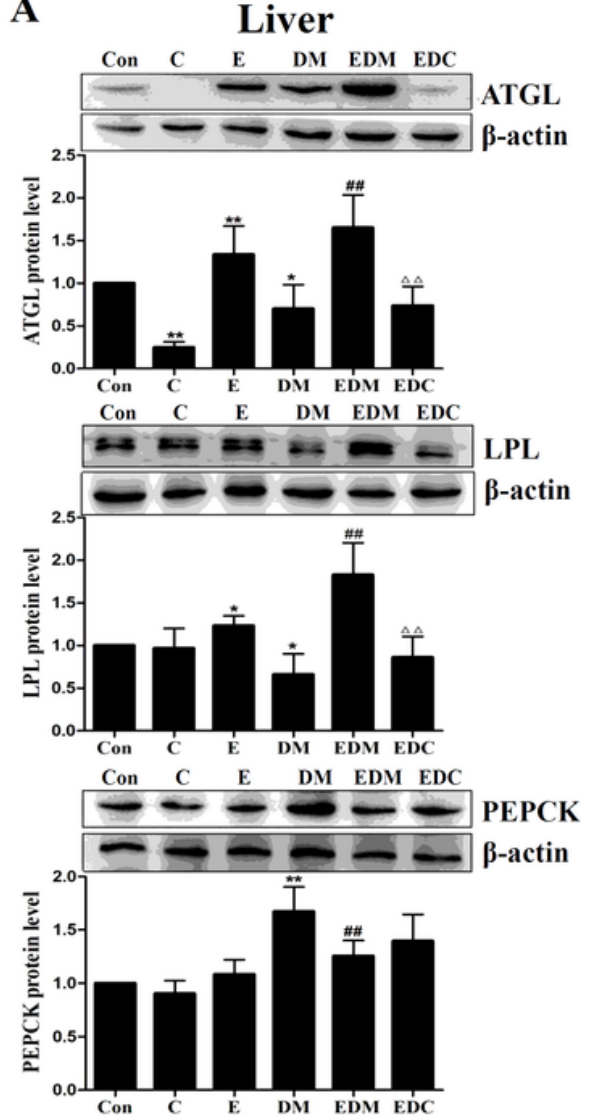

B
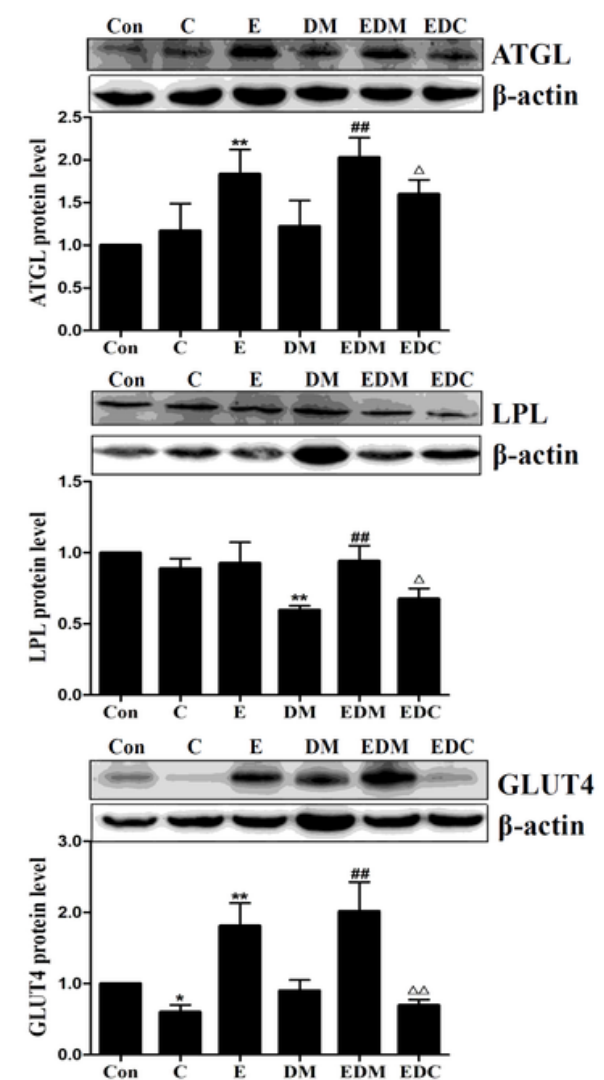

C Epididymal fat
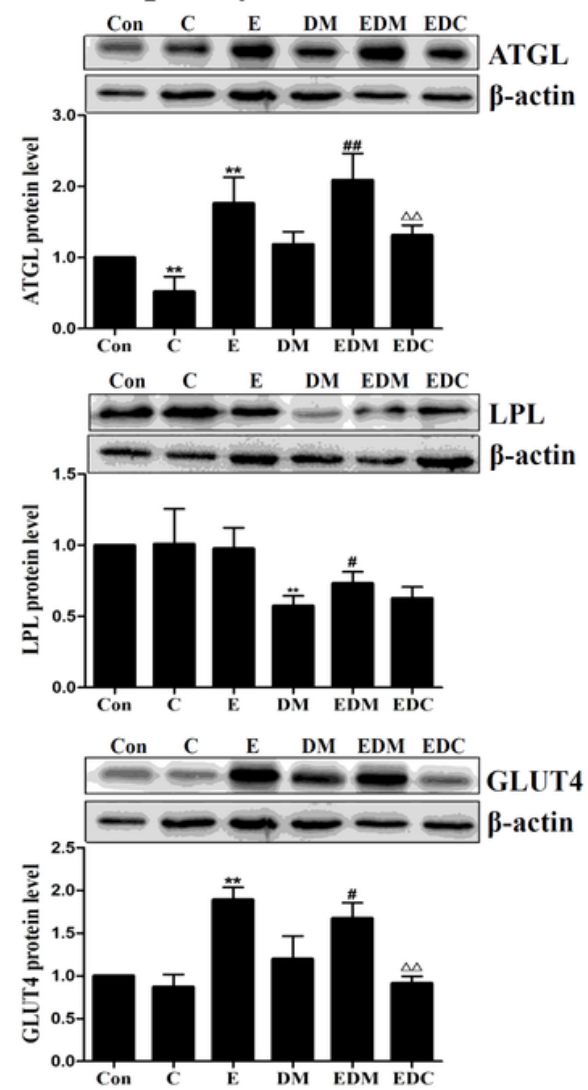

Figure 7

Effects of exogenous chemerin treatment on the protein levels of ATGL, LPL, GLUT4 and PEPCK in liver

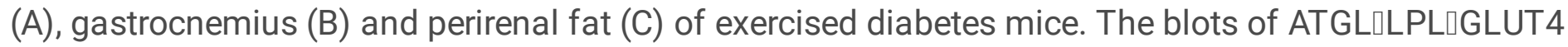
and PEPCK were quantified by Tanon software and normalized against $\beta$-actin, then the normalized numbers were compared and statistically analyzed (bottom). Con: control; C: chemerin treatment; E: exercise; DM: diabetes mellitus; EDM: exercised DM; EDC: EDM + chemerin treatment. *Pه0.05, ${ }^{\star \star} P \otimes 0.01$,

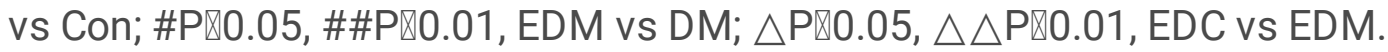

A

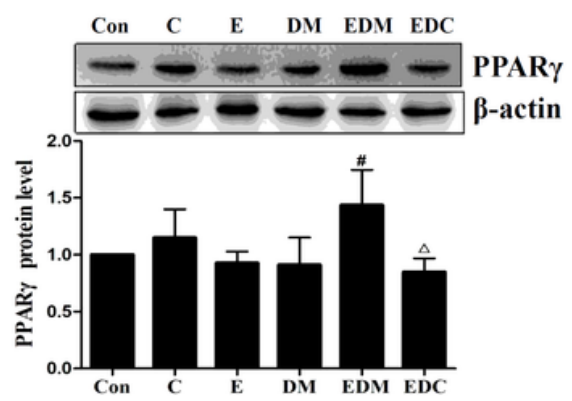

B

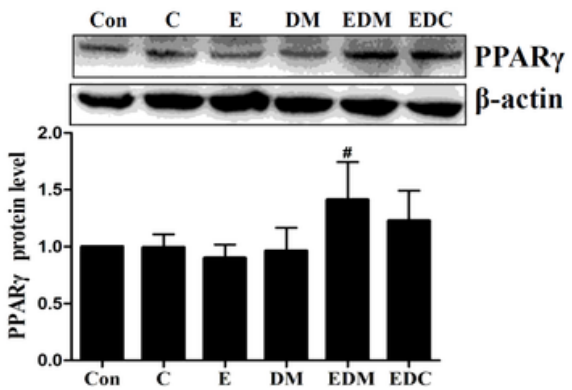

C Epididymal fat

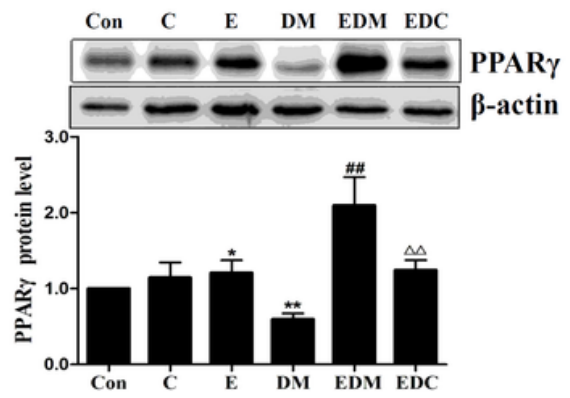




\section{Figure 8}

Effects of exogenous chemerin treatment on the protein levels of PPARy in liver (A), gastrocnemius (B) and epididymal fat (C) of exercised diabetes mice. The blots of PPARy were quantified by Tanon software and normalized against $\beta$-actin, then the normalized numbers were compared and statistically analyzed (bottom). Con: control; C: chemerin treatment; E: exercise; DM: diabetes mellitus; EDM: exercised DM;

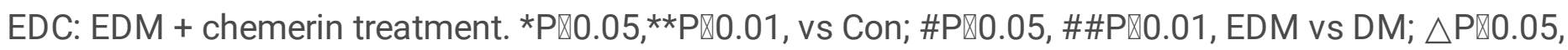
$\triangle \triangle \mathrm{P} \otimes 0.01, \mathrm{EDC}$ vs EDM. 